\title{
Some Observations Concerning Near-Wall PTV Measurements
}

Richard S. Skifton

Christian Cierpka (Technical University of Ilmenau, Germany)

Donald M. McEligot

July 2019

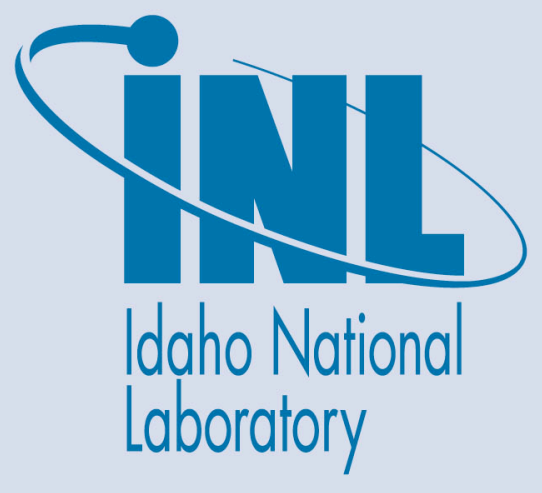

The INL is a U.S. Department of Energy National Laboratory operated by Battelle Energy Alliance 


\section{DISCLAIMER}

This information was prepared as an account of work sponsored by an agency of the U.S. Government. Neither the U.S. Government nor any agency thereof, nor any of their employees, makes any warranty, expressed or implied, or assumes any legal liability or responsibility for the accuracy, completeness, or usefulness, of any information, apparatus, product, or process disclosed, or represents that its use would not infringe privately owned rights. References herein to any specific commercial product, process, or service by trade name, trade mark, manufacturer, or otherwise, does not necessarily constitute or imply its endorsement, recommendation, or favoring by the U.S. Government or any agency thereof. The views and opinions of authors expressed herein do not necessarily state or reflect those of the U.S. Government or any agency thereof. 
INL/EXT-19-53771

Revision 0

\title{
Some Observations Concerning Near-Wall PTV Measurements
}

\author{
Richard S. Skifton \\ Christian Cierpka (Technical University of IImenau, Germany) \\ Donald M. McEligot
}

July 2019

\begin{abstract}
Idaho National Laboratory
Nuclear Science and Technology

Idaho Falls, Idaho 83415
\end{abstract}

http://www.inl.gov

\author{
Prepared for the \\ U.S. Department of Energy \\ Office of Nuclear Energy \\ Under DOE Idaho Operations Office \\ Contract DE-AC07-05ID14517
}





\begin{abstract}
In conjunction with an experimental study of entropy generation in bypasstransitional boundary layers, some considerations in the application of particle tracking velocimetry (PTV) have been examined. Treated are ideas on desirable spatial resolution, uncertainties in PTV algorithms and other uncertainties which may dominate plus the deduction of mean wall shear stress (or friction velocity) from mean velocity profiles determined with near-wall PTV.
\end{abstract}




\section{CONTENTS}

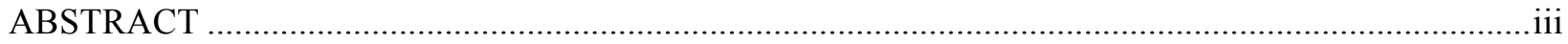

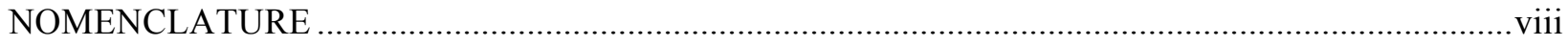

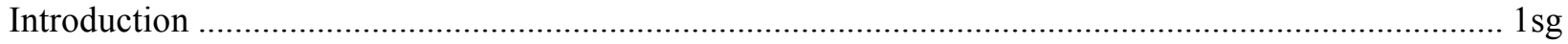

Flows examined

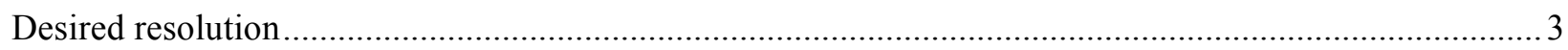

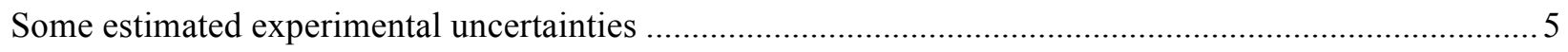

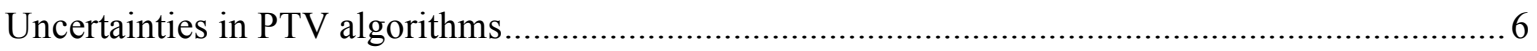

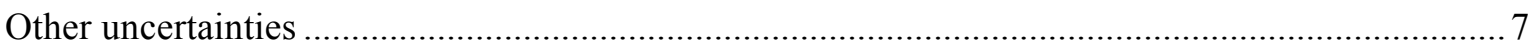

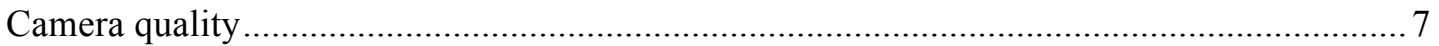

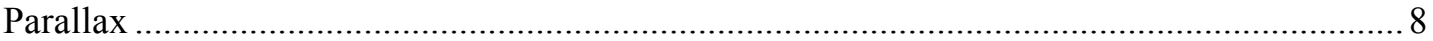

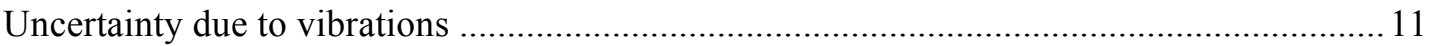

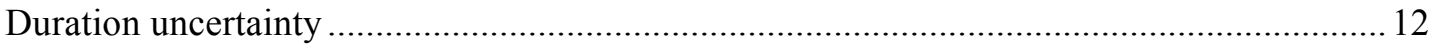

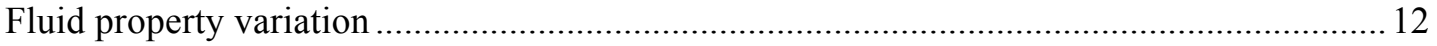

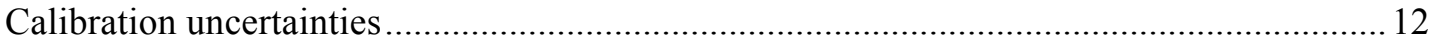

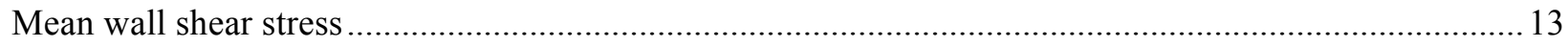

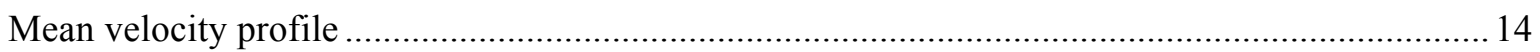

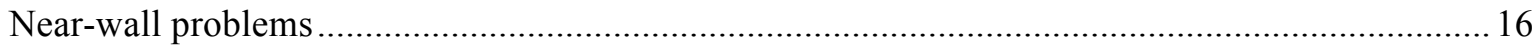

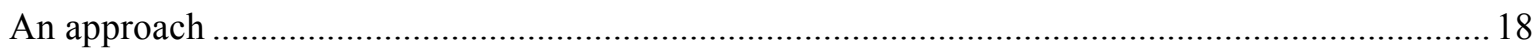

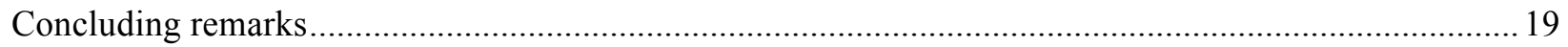

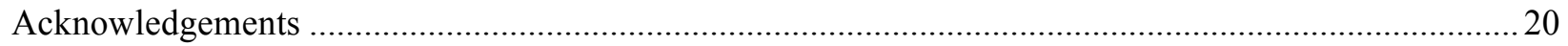

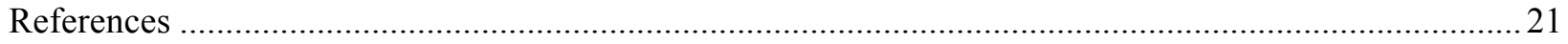

\section{FIGURES}

Fig. 1. Schematic diagram of INL Matched-Index-of-Refraction (MIR) test section configured for Case C, APG with TG. Flow is from right to left.

Fig. 2. Preliminary estimates of skin friction coefficients for the three cases (NPG $=$ negligible pressure gradient, $\mathrm{APG}=$ adverse pressure gradient).

Fig. 3. Geometry of light ray from near wall to PTV camera aperture in the MIR experiments, consistent with Figure 1A by Cierpka, Scharnowski and Kähler [2013]. Not to scale.

Fig. 4. "Screen shot" of instantaneous streamwise velocity measurements from a number of images with some (red circles) deduced from incorrectly shifted frames. Ordinate is displacement $\Delta x$ in pixels during interval $\Delta \mathrm{t}$ (therefore proportional to instantaneous streamwise velocity $\mathrm{u}$ ) and abscissa is vertical position y in pixels [Cierpka, e-mail 15 Oct 2013]

Fig. 5. Deviations from linear fit approximation in near-wall region of developed turbulent boundary layers as predicted with direct numerical simulations. 
Fig. 6. Preliminary results of mean streamwise velocity measurements in near-wall region by particle

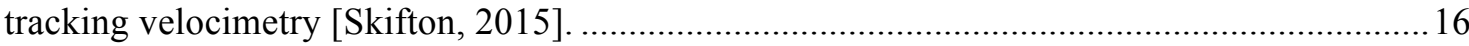

Fig. 7. "Parallax" geometry of near-wall measurements by particle tracking velocimetry with laser light sheets of finite thickness $\Delta \mathrm{z}$ and optical arrangement $\mathrm{A}$ from Figure 1 of Cierpka, Scharnowski and Kähler [2013].

Fig. 8. Near-wall measurements of Skifton [2015] analysed with PTV data acquisition code of Cierpka [Uni. der Bundeswehr, 16 October 2013]. Data = circles, quadratic fit $=$ dashed curve. 19

\section{TABLES}

Table 1. Some conditions of Skifton experiments [2015] 


\section{NOMENCLATURE}

\{ \} function of

C concentration; $\mathrm{C}_{\mathrm{p}}$, particle concentration

D diameter; $\mathrm{D}_{\mathrm{p}}$, particle diameter

$\ell \quad$ van Driest mixing length (equation 8)

$\mathrm{N} \quad$ number of independent realizations

$\mathrm{n} \quad$ refractive index

p pressure

$\mathrm{r}_{\mathrm{W}} \quad$ tube radius, $\mathrm{D} / 2$

S entropy generation rate; S", entropy generation rate per unit surface area; S"', pointwise entropy generation rate per unit volume

$\mathrm{T} \quad$ absolute temperature (except in equation 5)

$\mathrm{t} \quad$ time, thickness

$\mathrm{U}, \mathrm{V} \quad$ mean velocity components in streamwise and wall-normal directions, respectively

W width

$\mathrm{u}, \mathrm{v}, \mathrm{w}$ instantaneous velocity components in streamwise, wall-normal and spanwise directions, respectively

$\mathrm{u}^{\prime}, \mathrm{v}^{\prime}, \mathrm{w}^{\prime} \quad$ velocity fluctuations about means in streamwise, wall-normal and spanwise directions, respectively

$\mathrm{u}_{\mathrm{rms}} \quad$ root-mean-square streamwise velocity fluctuation

$\mathrm{u}_{\tau} \quad$ friction velocity, $\left(\tau_{\mathrm{W}} / \rho\right)^{1 / 2}$

unc(_) uncertainty of $\left(\_\right)$

$\mathrm{V}_{\mathrm{b}} \quad$ bulk velocity

$\mathrm{x}, \mathrm{y}, \mathrm{z} \quad$ coordinates in streamwise, wall-normal and spanwise directions, respectively; $\mathrm{y}_{\mathrm{p}}, \mathrm{z}_{\mathrm{p}}$, particle location in wall-normal and spanwise directions (Figure 3)

$\underline{\text { Non-dimensional quantities }}$

$\mathrm{C}_{\mathrm{d}} \quad$ dissipation coefficient, T S" / $\left(\rho \mathrm{U}_{\infty}^{3}\right)$

$\mathrm{C}_{\mathrm{f}} \quad$ skin friction coefficient, $2 \tau_{\mathrm{W}} /\left(\rho \mathrm{U}_{\infty}^{2}\right)$ or $2 \tau_{\mathrm{W}} /\left(\rho \mathrm{V}_{\mathrm{b}}^{2}\right)$

$\mathrm{D}^{+} \quad$ diameter in wall coordinates, $\mathrm{Du}_{\tau} / v$

$\mathrm{K}_{\mathrm{p}} \quad$ pressure gradient parameter, $\left(\mathrm{v} / \mathrm{\rho u}^{3} \tau^{3}\right) \mathrm{dp} / \mathrm{dx}$

$\mathrm{K}_{\mathrm{v}} \quad$ acceleration parameter, $\left(v / \mathrm{U}_{\infty}^{2}\right) \mathrm{dU} \infty / \mathrm{dx}$

$\operatorname{Re} \quad$ Reynolds number; $\mathrm{Re}_{\mathrm{x}}$, based on streamwise coordinate, $\mathrm{U}_{\infty} \mathrm{X} / \mathrm{v} ; \operatorname{Re} \delta$, based on boundary layer thickness, $\mathrm{U}_{\infty} \delta / v ; \operatorname{Re} \theta$, based on momentum thickness, $\mathrm{U}_{\infty} \theta / \nu$

$\mathrm{U}^{+} \quad$ streamwise mean velocity in wall coordinates, $\mathrm{U} / \mathrm{u}_{\tau}$

$\mathrm{x}^{+} \quad$ streamwise coordinate, $\mathrm{xu}_{\tau} / v$

$\mathrm{y}^{+} \quad$ wall-normal coordinate, $\mathrm{yu}_{\tau} / v$

$\mathrm{z}^{+} \quad$ spanwise coordinate, $\mathrm{zu}_{\tau} / v$

$\varepsilon^{+} \quad$ rate of turbulent dissipation of turbulence kinetic energy (TKE), $v \varepsilon / \mathrm{u}_{\tau}{ }^{4}$

$\lambda^{+} \quad$ Kolmogov length scale, $\lambda \mathrm{u}_{\tau} / \nu$

$\lambda_{\theta} \quad$ Thwaites (acceleration/pressure gradient) parameter [1949; White,

Sec. 4-6.6, 1991], $\left(\theta^{2} / v\right) \mathrm{d} \mathrm{U}_{\infty} / \mathrm{dx}$ 


\section{Greek symbols}

$\delta \quad$ boundary layer thickness

$\varepsilon \quad$ rate of turbulent dissipation of TKE

$\theta \quad$ momentum thickness

$\kappa \quad$ von Karman constant, usually about 0.4

$\lambda \quad$ Kolmogorov length scale, $\left(v^{3 / \varepsilon}\right)^{1 / 4}$

$\mu \quad$ absolute viscosity

$v \quad$ kinematic viscosity, $\mu / \rho$

$\rho \quad$ density

$\sigma \quad$ standard deviation [Taylor, Sec. 4.2, 4.4 and 5.4, 1997]

$\tau \quad$ shear stress; $\tau_{\mathrm{W}}$, wall shear stress

$\Phi \quad$ dissipation function (equation 3.62 by Schlichting and Gersten [2000])

$\phi \quad$ angle in parallax description (Figure 3)

\section{Subscripts}

$\begin{array}{ll}1,2,3 & \text { indices } \\ \text { in } & \text { inlet, entry, } \mathrm{x}=0 \\ \mathrm{p} & \text { particle, point } \\ \mathrm{rms} & \text { root-mean-square fluctuation } \\ \mathrm{t} & \text { turbulent } \\ \mathrm{w}, \text { wall } & \text { evaluated at wall temperature } \\ \infty & \text { freestream }\end{array}$




\section{Some Observations Concerning Near-Wall PTV Measurements \\ INTRODUCTION}

The problem ultimately being addressed is entropy generation (or turbulent dissipation) in bypass transition [Walsh et al., 2011] or turbulent wall flows [McEligot et al., 2008]. Typically the pointwise entropy generation $\mathrm{S}^{\prime \prime}$ is concentrated in the near-wall region of boundary layers and determining its instantaneous rate

$$
\begin{aligned}
& \mathrm{S}^{\prime \prime \prime}=(\mu / \mathrm{T}) {\left[2(\partial \mathrm{u} / \partial \mathrm{x})^{2}+2(\partial \mathrm{v} / \partial \mathrm{y})^{2}+2(\partial \mathrm{w} / \partial \mathrm{z})^{2}+((\partial \mathrm{v} / \partial \mathrm{x})\right.} \\
&\left.+(\partial \mathrm{u} / \partial \mathrm{y}))^{2}+((\partial \mathrm{w} / \partial \mathrm{y})+(\partial \mathrm{v} / \partial \mathrm{z}))^{2}+((\partial \mathrm{u} / \partial \mathrm{z})+(\partial \mathrm{w} / \partial \mathrm{x}))^{2}\right]
\end{aligned}
$$

involves evaluating the instantaneous spatial gradients of various velocity components. Here $\mathrm{u}, \mathrm{v}$ and $\mathrm{w}$ are the velocity components in the $\mathrm{x}, \mathrm{y}$ and $\mathrm{z}$ directions, respectively. (One can see that this equation can be written as $S^{\prime \prime \prime}=\Phi / T$ where $\Phi$ is the dissipation function [eqn. 3.62, Schlichting and Gersten, 2000].) Precise measurements are also needed in this near-wall region to determine the wall shear stress for the skin friction coefficient $\mathrm{C}_{\mathrm{f}}$ and presentation in wall coordinates. And evaluation of the energy dissipation coefficient $C_{d}$ (or integral entropy generation rate) involves evaluation of Reynolds shear and normal stresses there [Rotta, 1962].

As shown by Kähler, Scharnowski and Cierpka [2012a,b] particle tracking velocimetry (PTV) can give better spatial resolution and smaller estimated experimental uncertainties as a surface is approached than particle image velocimetry (PIV) techniques do. Accordingly, the aim of this discussion is to examine some of the possible problems occurring in the application of some PTV approaches to measurement of the quantities mentioned above, especially the instantaneous velocity components and their gradients, in the near-wall region. In particular, the present note addresses planar PTV applications yielding two velocity components in two directions although some of the uncertainties treated occur in other PTV systems as well.

A comparable report of the examination of possible problems of $P I V$ measurements in the oil tunnel of the Matched-Index-of-Refraction (MIR) flow system at Idaho National Laboratory (INL) has been presented by McEligot, McIlroy and Johnson [INL/EXT-07-13529]. For understanding uncertainty estimation for measurements and deduced results, the reader is referred to the publications of Kline and McClintock [1955], Moffat [1982; 1988], Kline [1985] and Abernathy, Benedict and Dowdell [1989] and to the text of Taylor [1997]. In addition to the journal and report literature, useful background on PIV and to some extent PTV is provided by the "handbooks" of Raffel et al., [3rd edition, 2018] and of Adrian and Westerweel [2011]. The third edition by Raffel et al. has two additional authors and is about twice as thick as the second edition [2007]; it has extended its section on PTV to about fourteen pages rather than about a half page. A new chapter on PIV experimental uncertainties has also been added. Adrian and Westerweel have a 3-1/4 page section on PTV in their introductory chapter and then their chapter on low image density (49 pages) primarily applies to PTV. A detailed user's guide to an OSU/INL/ISU (Ohio State/INL/Idaho State U.) three-dimensional PTV system has been drafted by McCreery [ISU 2011]; this system uses a stroboscopic white light source rather than lasers.

\section{FLOWS EXAMINED}

To illustrate with quantitative examples, the current note considers measurements of three flat plate flows in the INL MIR flow system [Stoots et al., 2001; McIlroy and Budwig, 2007; McIlroy, Becker and McEligot, 2011] by Richard Skifton [2015]. The three are 
- Case A. "Zero" pressure gradient (ZPG) without any turbulence generator (TG)

- Case B. "Zero" pressure gradient with turbulence generator

- Case C. Adverse pressure gradient (APG) with turbulence generator.

The first two are aimed at providing data for comparison to well-studied situations in a primarily laminar boundary layer and a developing turbulent one, respectively, in order to qualify the measurements. These two might better be designated as negligible pressure gradients (NPG) since the streamwise pressure gradient attained is not exactly zero, particularly near the entry. The third is intended to provide new fundamental data for entropy generation rates for bypass transition in an adverse pressure gradient (Figure 1). The wall-normal direction will be described as vertical and streamwise as horizontal at times in the following discussions. More complete descriptions of these experiments are found in the thesis by Skifton and a subsequent paper by Skifton et al. [2017].

The test plate is horizontal with transparent quartz sections for the laser light sheets to pass through from below. A single camera is then mounted on a traverse with viewing horizontally through the side windows of the MIR test section focusing on the flow above the plate. Consequently, the measurement system is considered 2C2D (two velocity components on a two-dimensional plane) so the present report primarily concerns such systems. A commercial PIV/PTV system is employed for the data acquisition and data analysis. The working fluid is a light mineral oil held at a constant temperature of $25.156+/-$ $0.005 \mathrm{C}$ to match the refractive index of the transparent quartz used in sections of the flat plate model. At this temperature the fluid density is $0.830+/-0.0002 \mathrm{~g} / \mathrm{mL}$ and the kinematic viscosity is $1.325 \times 10^{-5}+/-$ $0.0078 \times 10^{-5} \mathrm{~m}^{2} / \mathrm{sec}$ [Budwig and Westin, 2011]. Some conditions of the experiment are summarized in Table 1 and preliminary experimental results for the skin friction coefficient are presented as Figure 2.

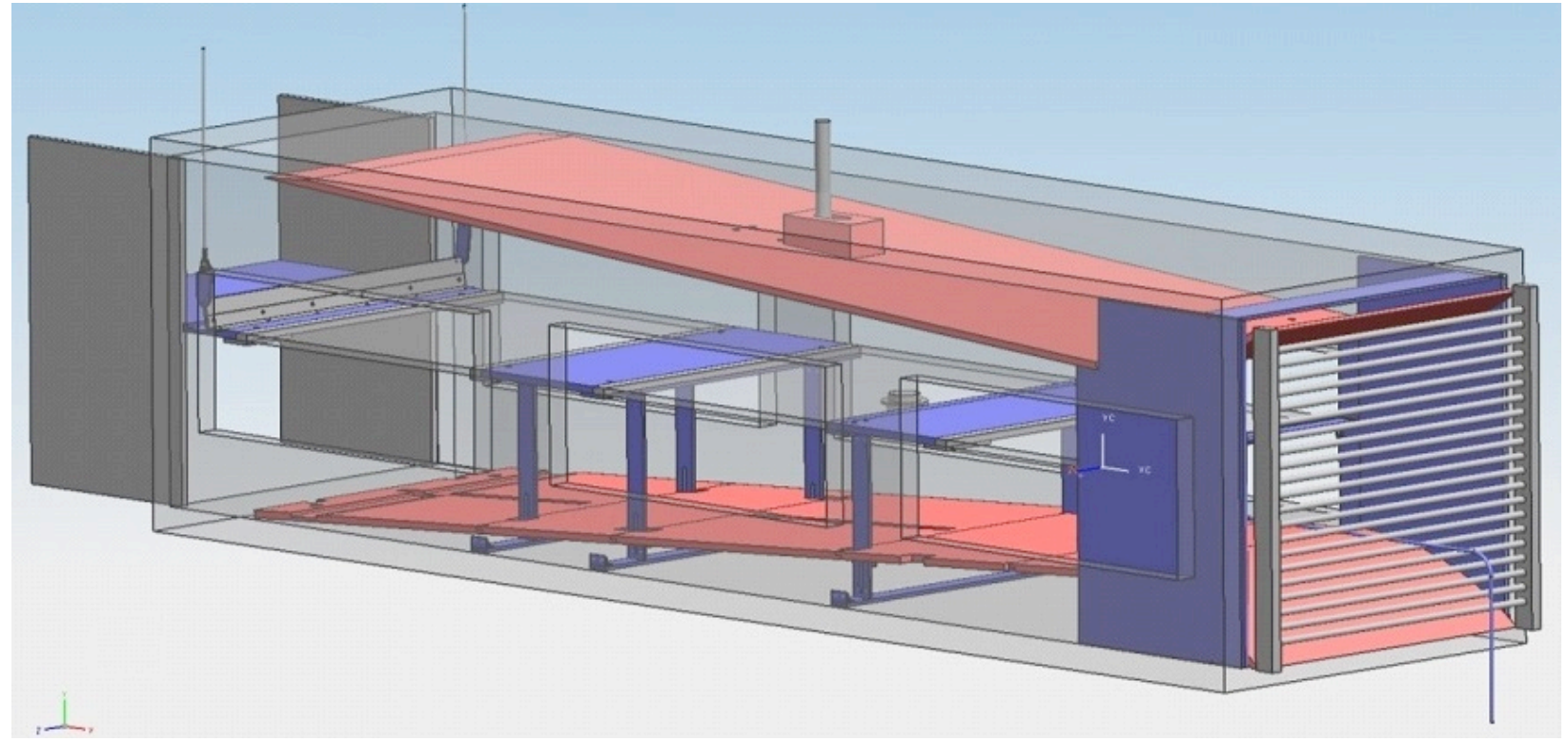

Fig. 1. Schematic diagram of INL Matched-Index-of-Refraction (MIR) test section configured for Case C, APG with TG. Flow is from right to left. 
Table 1. Some conditions of Skifton experiments [2015].

\begin{tabular}{l|l|l|l} 
& $\begin{array}{l}\text { Case A } \\
\text { ZPG w/o TG }\end{array}$ & $\begin{array}{l}\text { Case B } \\
\text { ZPG w/TG }\end{array}$ & $\begin{array}{l}\text { Case C } \\
\text { APG w/TG }\end{array}$ \\
\hline $\mathrm{U}_{\infty, \text { in }}(\mathrm{m} / \mathrm{s})$ & 1.67 & 1.45 & 2.79 \\
\hline$\delta_{\text {in }}(\mathrm{mm})$ & 6.24 & 6.50 & 6.71 \\
\hline $\mathrm{Re}_{\delta \text {,in }}$ & 786 & 710 & 1417 \\
\hline$\left(\mathrm{u}_{\infty, \mathrm{rms}} / \mathrm{U}_{\infty}\right)_{\text {in }}$ & 0.57 & 6.45 & 4.05 \\
\hline$\lambda_{\theta, \text { in }}$ & 0.0216 & 0.022 & $-0.083(?)$ \\
\hline $\operatorname{Re}_{\mathrm{x}}$ & $28,840-271,100$ & $5301-246,000$ & $19,580-330,100$ \\
\hline $\operatorname{Re}_{\theta}$ & $138.7-314.3$ & $67.0-655$ & $167.1-2637$
\end{tabular}

To measure the gradients needed to calculate S"', one would like to know the sizes of the smallest shear layers occurring so the desirable spatial resolution or spacing between measurements can be chosen, if possible. Therefore, this note attempts to develop very approximate estimates (hopefully, a bit better than order-of-magnitude) of the smallest shear layer thicknesses in the near wall-region of laminar, transitional and turbulent boundary layers from some existing literature so that appropriate control parameters might be chosen for measurement techniques proposed.

\section{DESIRED RESOLUTION}

Insight into potential spatial resolution and experimental uncertainty levels for particle tracking and particle image velocimetry (PTV/PIV) is provided by Kähler, Scharnowski and Cierpka [2012a,b]. In this note the focus is on estimating what spatial resolution the investigator would like to have.

The Kolmogorov length scale $\left(\lambda=\left[v^{3} / \varepsilon\right]^{1 / 4}\right)$ which is the length scale of "locally isotropic turbulence" [Rotta, pp. 38-9, 1962] is derived from an analysis treating homogeneous, isotropic turbulence as in the freestream of a high-Reynolds-number turbulent boundary layer. Here $v$ is the kinematic viscosity and $\varepsilon$ is the mean dissipation rate of turbulent kinetic energy. It is considered to be a measure of the size of the eddies dissipated via viscous action in this situation. Whether it has any physical meaning near the wall of a turbulent or transitional boundary layer --- where the turbulence is typically anisotropic --- is not clear to this author. The definition of Kolmogorov length scale can be converted to

$$
\lambda^{+}=\left(\varepsilon^{+}\right)^{-1 / 4}
$$

in wall coordinates via their definitions. From the direct numerical simulations (DNS) employed by Walsh et al. [2011] one can see that the highest turbulent dissipation rate is near the wall and it had a range of $0.05<\varepsilon^{+}<0.4$ approximately. These values give a range of about 2.1 to 1.4 for $\lambda^{+}$.

Nolan and Zaki [2013] applied conditional sampling to their pre-transitional laminar boundary layer to examine the width of the "streaks" evolving (and other quantities). Their Figure 19 shows the width of 
their streaks $\mathrm{W}$ to be about the order of the boundary layer thickness $\delta$. If we estimate that a "high" shear region between streaks is about ten per cent of the width, then it would be about $0.1 \delta$.

RS-Cf\{Reth\}-PGcomp.qpc

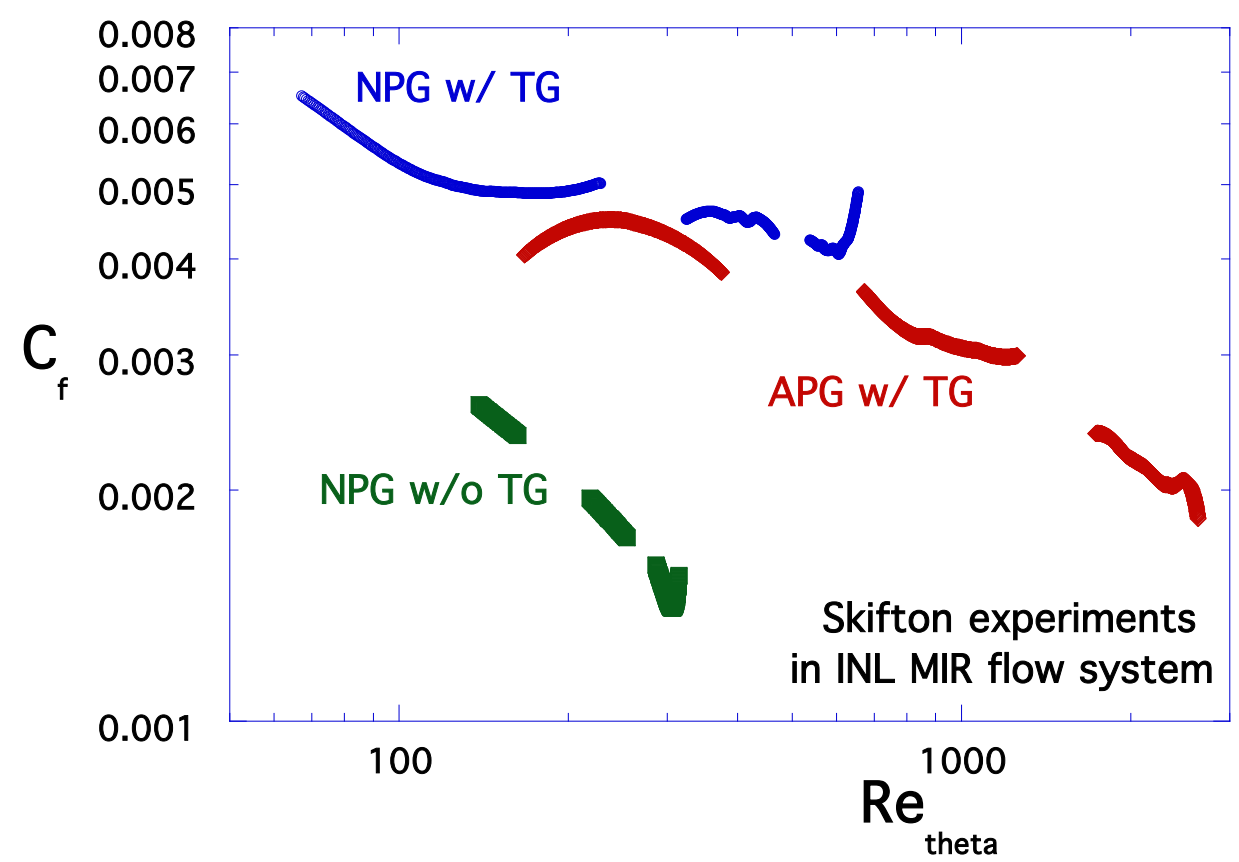

Fig. 2. Preliminary estimates of skin friction coefficients for the three cases (NPG $=$ negligible pressure gradient, $\mathrm{APG}=$ adverse pressure gradient).

For the transitional boundary layer, Figure 28 by Nolan and Zaki gives some insight into approximate turbulent spot dimensions, Early in their development the spot height is about $(2 / 3) \delta$ and the width about $(5 / 3) \delta$. "Irregularities" in the spot shape appear to be of the order $\delta / 3$. Again, if we estimate the shear layer surrounding the turbulent spots is about ten per cent of its characteristic size, we could imagine shear layers of thickness about $\delta / 30$ possibly being present.

Corino and Brodkey [1969] sketched a "typical" ejection in the wall layer of a turbulent flow as having a "diameter" $\mathrm{D}^{+}$of about six to seven. If the maximum shear layer around such an ejection is about twenty per cent of its diameter, its thickness $\Delta \mathrm{z}^{+}$or $\Delta \mathrm{x}^{+}$would be about 1.2 or so. In the wallnormal direction, a shear layer thickness as thin as $\Delta \mathrm{y}^{+} \approx 1-1 / 4$ was depicted.

The hydrogen-bubble flow visualizations of Kasagi, Hirata and Nishino [1986] show outflow in the near-wall region ("low-speed" streak) of width $\Delta \mathrm{W}^{+} \approx 20$ with the steepest section being about twenty per cent of that (their Figure 6); thus, the peak shear layer appears to be $\Delta \mathrm{z}^{+} \approx 4$ in thickness. This structure would probably register as an ejection in the studies of Brodkey and colleagues. From the streamlines in their Simple Pseudo-Vortical Motion model (their Figure 16) one can estimate that the regions of strongest velocity gradients in the low- and high-speed streaks are $\Delta \mathrm{z}^{+} \approx 5$.

From stereo PIV data, Kähler [2004] provides some contour plots of instantaneous uv at $\mathrm{y}^{+}$about 10 , 20 and 30 in his Figures 13 and 14 and identifies ejections. Their widths appear to be about 15, 20 and 35 in wall units. The shear layers around these ejections seem approximately half their widths, i.e., $\Delta \mathrm{z}^{+}$or 
$\Delta \mathrm{x}^{+}$about eight for the smallest. However, he notes that these ejections have low probabilities of occurrence so they contribute little to the mean Reynolds shear stress.

Lin et al. [2008] obtained PIV measurements of streaks in the near-wall region of a turbulent boundary layer. They determined the narrower low speed streaks to have widths $\mathrm{W}^{+} \approx 31+/-16$ giving $\mathrm{W}^{+}$about 15 for the narrowest. If the maximum shear layer in this region is about ten to twenty per cent of its width, the shear layer thickness $\Delta \mathrm{z}^{+}$might be about 1.5 or so.

For the viscous layer of a low-Re turbulent channel flow, McEligot, Brodkey and Eckelmann [2009] obtained simultaneous signals of instantaneous $\mathrm{u}, \mathrm{v}$ and wall shear stress by hot film anemometry. With conditional sampling they were then able to construct ensemble-averaged, simultaneous values of $u$ and $v$ at several positions and analyze them for various phenomena; the widths of apparent sweeps were about $\Delta \mathrm{x}^{+}$of forty (their figure 3 ).

In summary, of the limited number of studies in this examination, the most restrictive shear layer sizes observed were estimated to be about $\delta / 30$ for laminar and transitional boundary layers and $\Delta \mathrm{z}^{+}$or $\Delta \mathrm{x}^{+} \approx 1.2$ and $\Delta \mathrm{y}^{+} \approx 1.3$ for turbulent flows. The investigator then must choose how few points could be measured within the layer to describe it, possibly three or four using a quadratic or cubic fit (particle spacing of $\Delta \mathrm{xp}^{+} \approx 0.6$ or 0.4 , respectively). Whether this resolution can be achieved in a given experiment will depend on its conditions (parameters) and its PTV/PIV system. Many DNS grids do not provide this resolution in spanwise or streamwise directions.

\section{SOME ESTIMATED EXPERIMENTAL UNCERTAINTIES}

Kline $\{1985$ ] suggested "Uncertainty analysis is an essential ingredient in planning, controlling and reporting experiments. The important thing is that a reasonable uncertainty analysis be done." However, as noted by Lassahn [1985], experimental uncertainty is often undefined or not well defined in the process of uncertainty or error analysis. Kline defines an error in measurement as "the difference between the true value and the recorded value" and then an uncertainty as "a possible value that the error might take on in a given measurement." (Others treat the two words as being interchangeable.) NIST [2019] uses the definition from the ISO Guide to the Expression of Uncertainty in Measurement which they cite as the uncertainty of measurement being a "parameter, associated with the result of a measurement, that characterizes the dispersion of the values that could reasonably be attributed to the measurement." The NDT Resource Center [2014] expresses the uncertainty as "a parameter characterizing the range of values within which the value of the measurement can be said to lie within a specified level of confidence." The Science Education Research Center of Carleton University [SERC 2019] indicates their usage of uncertainty "means the range of possible values within which the true value of the measurement lies." Allain [2019] defines uncertainty as "the experimenter's best estimate of how far an experimental quantity might be from the 'true value';" his description is the sense in which we tend to use the term.

Some instantaneous velocity profiles in the present experiment appear to have large scatter so it is appropriate to examine whether this appearance is due to turbulent fluctuations or whether it can represent experimental uncertainties [Kline and McClintock, 1955; Kline, 1985; Moffatt, 1988]. PTV uncertainties have been considered by Kähler and colleagues [Cierpka and Kähler, 2012; Kähler, Scharnowski and Cierpka, 2102b; Scharnowski, Bross and Kähler, 2019]. The experimental uncertainties may be separated into two categories: (1) uncertainty of the PTV algorithm in determining the instantaneous locations of the individual particle centers and (2) other uncertainties. Many (most?) studies of PIV and PTV uncertainties have concentrated on the former, often by employing synthetic "data" [Theunissen, Stitou and Riethmuller, 2004; Cierpka and Kähler, 2012; Kähler, Scharnowski and Cierpka, 2102b]. However, uncertainties from other effects can be larger and, therefore, more important.

PIV and PTV literature often reports standard deviations $\sigma$ as values of the random experimental uncertainties. However, the standard deviation corresponds to having about 68 per cent of the values 
likely to fall within a value $\sigma$ of the true value [Taylor, Sec. 5.4 and 5.8, 1997]. But many experimentalists prefer to report uncertainties in terms of "twenty-to-one odds" corresponding to about $2 \sigma$ (95.4 per cent probability) [Kim, Simon and Viskanta, 1993]. In this note, we will try to report quantitative random uncertainties as $2 \sigma$.

\section{Uncertainties in PTV algorithms}

Cierpka and Kähler [2012] examined errors in tracking algorithms for the determination of the individual particle position. They considered five different strategies using synthetic images. The performance was predicted for variations of signal-to-noise ratio (SNR), "bit depth," particle image diameter $\mathrm{D}_{\mathrm{p}}$ and particle image density. It was shown that accuracy depends strongly on the particle image diameter, the image sampling and SNR. For particle images larger than $D_{p}$ about $3 \mathrm{px}$, the particle center can be detected "accurately" and SNR should be ten or higher.

The PTV algorithm used by Skifton for some of his data presented here apparently is the approach by Theunissen, Stitou and Riethmuller [2004]. Their so-called individual particle correlation (IPC) method is an iterative process which correlates small windows centered around the particle image in successive frames, displacing them until convergence is reached. Theunissen, Stitou and Riethmuller (TSR) employed synthetic images to demonstrate the accuracy of the algorithm with $\mathrm{D}_{\mathrm{p}}=3 \mathrm{px}$, "typical" particle concentration $\mathrm{C}_{\mathrm{p}}=0.1 \mathrm{ppp}$ and windows of $5 \times 5 \mathrm{px}^{2}$. This seeding give average spacing of about $3.2 \mathrm{px}$. The uniform velocity of the simulation corresponded to displacement $\Delta \mathrm{x}=1.5 \mathrm{px}$. Their resulting random error (standard deviation) was in the range $0.05-0.1 \mathrm{px}(\sim 3.3-6.7$ per cent). In a comparable simulation with homogeneous fluctuations, mean errors appear to be of the order of 0.2 to $0.4 \mathrm{px}$. Estimates of errors for the parameter ranges of the present data do not appear to be available.

The TSR results for standard deviation of displacement $\Delta \mathrm{x}$ in their example for uniform velocity correspond approximately to those of Cierpka and Kähler [2012] for their technique labeled "twodimensional correlation with a Gaussian function (GC)." For the present image parameters $\left(\mathrm{D}_{\mathrm{p}}\right.$ about 3.5 px and $\mathrm{C}_{\mathrm{p}}$ about $0.005 \mathrm{ppp}$ giving estimated particle overlap of five per cent or less), GC gives a standard deviation of about $0.03 \mathrm{px}$ for the error in determining particle positions. With the UniBw (Universität der Bundeswehr München) in-house code, the standard deviation in particle location is estimated to be about 0.05-0.1 px [Cierpka, e-mails 29 Aug 2013, 16 Oct 2015]. The random uncertainty of the particle displacement between two images would be estimated as unc $(\Delta \mathrm{x}) \approx\left[\left(\text { unc }_{2}\right)^{2}+\left(\text { unc }_{1}\right)^{2}\right]^{1 / 2}$ or about 1.4 times the individual uncertainties if they are approximately the same.

The 2nd PIV Challenge [Stanislas et al., 2005] examined the performance of PTV algorithms by four groups for two test cases; (A) a turbulent jet experiment and (B) DNS of a turbulent channel flow. The algorithms included one based on the method of Stitou and Riethmuller [2001]. The PTV algorithm used in the software for the present results apparently is as described by Theunissen, Stitou and Riethmuller [2004] based on the method of Stitou and Riethmuller; thus, the VKI results for the synthetic DNS wall shear layer (their Case B) would be the ones pertinent here.

For the DNS case, particle image diameter was about $1.3 \mathrm{px}$ at one standard deviation and $2.6 \mathrm{px}$ at two; it was optimized for PIV. Stanislas et al. concluded that the resulting difference between the deduced value and the DNS value for the mean streamwise velocity was of the order of $0.5 \mathrm{px}$ for the VKI method and some other PTV teams (their Fig. 14b). Profiles of the "RMS error of the streamwise velocity component" (presumably standard deviation) are presented in their Figure 18; the VKI results seem to be about $0.25 \mathrm{px}$ for most of the profile. Comparisons of instantaneous velocity fields, of interest to our present study, are supposedly available on the Challenge web site. Stanislas et al. concluded that, at the time of the study, synthetic images were not yet fully representative of real images.

Wieneke and Sciacchitano [2015] have demonstrated the propagation of uncertainties of instantaneous velocities to other desired quantities like mean velocity profiles, turbulence statistics, 
vorticity, gradients, etc., focusing on random uncertainties. Systematic (bias) uncertainties are neglected. Formulae presented are useful for both PIV and PTV. However, they concentrate on uncertainties in velocity components and apparently neglect the uncertainty in spatial location that can become significant in calculating gradients, vorticity, dissipation and such. In contrast to some others, they include consideration of possible correlations between individual velocity components, such as $\mathrm{u}^{\prime}$ and $\mathrm{v}^{\prime}$ which are known to be correlated near a wall [McEligot and Eckelmann, 2006]. They point out that the deduced uncertainty in Reynolds shear stress is moderated by the cross-correlation coefficient between the uncertainties of $u$ and $v$. And they emphasize that the number of independent realizations to be used in the formulae can be much less than the numbers of images collected due to sampling rate and duration (e.g., orders of magnitude).

The theoretical studies considered in this section predicted a range of random uncertainties $(2 \sigma)$ in particle displacements between images of about 0.1 to $0.3 \mathrm{px}$. The only one to address systematic uncertainties (TSR) appeared to estimate about 0.4 to $0.8 \mathrm{px}$. If one assumes these values for individual realizations to be approximately constant, they will be moderated when averaging to deduce temporal mean values as unc (mean $\mathrm{U}) \approx \operatorname{unc}($ inst $\mathrm{u}) / \mathrm{N}^{1 / 2}$ where $\mathrm{N}$ is the number of independent realizations. However, the more realistic comparison of PTV results to DNS calculations in the 2nd PIV Challenge yielded differences in mean streamwise velocities of the order of 0.5 px [Stanislas et al., 2005].

\section{Other uncertainties}

The expected uncertainties for the PTV algorithms have been shown to be fairly small under the idealized conditions of analytical predictions. So a consequent question is ----- what further uncertainties are introduced in realistic experimental conditions? Analysts typically assume implicitly that sensitivity of each "pixel" across its area is the same, that their positioning and spacing are perfect, that there are no optical imperfections between the FoV (field of view) and the sensors, etc.

\section{Camera quality}

Concerning the sensitivity of individual pixels in their matrix, Hain, Kähler and Tropea [2007] compared the properties of digital cameras typically employed for PTV/PIV methods. They examined sensitivity, linearity, SNR and image uniformity of various cameras. Of the cameras, the PCO Sensicam was the only CCD camera tested and it showed the best overall performance; accordingly, it was recommended for high precision measurements. It is a 12 bit camera. The camera used in the present experiment is comparable to the PCO Sensicam [Hain, e-mail 20 Nov 2015].

The PCO Sensicam showed best image uniformity of the cameras considered. Its spatial standard deviation was calculated to range between about 1-1/2 and 2-1/2 per cent of the average intensity. Their Figure 8a shows the pixel-to-pixel variation of the image uniformity along a wall normal profile. Across the FoV $\mathrm{S}_{\text {unif }}\{\mathrm{x}, \mathrm{y}\}$ varies gradually by about five per cent (expanded data from R. Hain [e-mail 20 Nov 2015]). However, over the range about $0.5<\left(\mathrm{y} / \mathrm{L}_{\mathrm{y}}\right)<0.9$ it is reasonably constant with a normalized average of about 0.305 and standard deviation of 0.0013 , equivalent to a pixel-to-pixel uncertainty of 0.9 per cent of the intensity. Since it is a 12 bit camera, the reading or recording uncertainty due to round-off error would be about +/- 0.00012 normalized units, small compared to the standard deviation. A further question would be --- how might such variations affect the determination of a particle centroid position with a specific PTV algorithm and, therefore, the uncertainty of the particle position. This question could be addressed with synthetic data by varying the intensities with random noise of the order evaluated by Hain, Kähler and Tropea.

Since a typical particle image diameter is several pixels, variations in the responses of individual pixels will affect the apparent particle centroid (i.e., measured location) relative to its true location. The magnitude of the effect can be expected to depend on the diameter and "quality" of the particle image, the procedure for deducing the location and the distribution of the pixel sensitivities as well as other factors. This effect was partially studied at Uni. der Bundeswehr when developing a simultaneous temperature 
measurements technique; however, the emphasis of that study was on the overall intensity rather than the position [Cierpka e-mail 2 April 2019]. This question could be answered by the change in signal-to-noise ratio (SNR) with the synthetic data, since a different change in individual response would result in a random distribution of the intensity values. It was also shown that, with eight bits or more, for $\mathrm{D}_{\mathrm{p}}>3 \mathrm{px}$ the accuracy of the center detection does not improve with the addition of more digits (Figure 2 by Cierpka and Kähler [Lisbon 2012]). Since the number of pixels used for the position determination is of the order of at least $\mathrm{D}^{2}(\sim$ ten pixels), the variation of the intensity of a single pixel has only a negligible effect on the determination of the particle image center and we assume that as long as the individual change is small the center determination is not affected. If the intensity of the whole particle image happens to change (e.g., if the laser intensity changes between pulses), this difference also does not affect the center determination as all pixels involved would be subject to the same intensity change. Further, very often a so-called dark image (usually for CMOS sensors) without illumination is taken prior to the measurements and subtracted later to minimize offset effects due to different pixel dark signals.

Another measure of camera quality would be the uncertainties in the actual locations of the pixels. We have not yet found any reports of such estimates from manufacturers. Indications should be given by the design tolerances of the manufacturers and any tests they make to check that their specifications are met. Conventional wisdom [Anderson, e-mail 25 April 2019; Smith, e-mail 26 April 2019] is that errors in pixel position are negligible compared to other uncertainties in PTV measurements. In any event, pixel position errors may be partially treated --- along with some other uncertainties --- in the calibration process (which introduces its own uncertainties). In a related study of sub-pixel sensitivity variations of a CCD camera, Abdelsalam, Stanislas and Coudert [2014] concluded that the error in pixel optical center position relative to the geometric center was about one-tenth of the pixel size. The groups of optical engineering, manufacturing and industrial imaging at TU Ilmenau also assume a pixel position uncertainty of $0.1 \mathrm{px}$ for uncorrected images as a rule-of-thumb [Cierpka, e-mail 16 May 2019]. However, how much this error influences the position estimation after employing the calibration plate is not evident to us. Also, since with a particle image of $\mathrm{D}_{\mathrm{p}}=3 \mathrm{px}$ about ten pixels would be used in determining the apparent center, it is expected that this effect would be reduced.

\section{Parallax}

Parallax is defined as "the apparent displacement .... . of an object as seen from two different points" [Neilson, 1959]. In PIV/PTV techniques it is involved in determining the apparent location of a particle within a planar light sheet of finite thickness $\Delta z$. In this case the two points could be considered to be the camera aperture and the origin of the coordinate system.

The importance of parallax in 2-D PIV and PTV systems has been examined by Cierpka, Scharnowski and Kähler [2013]. They treated three optical arrangements used near a surface. Of these, the present experiments employed their Configuration A in their Figure 1, thereby maximizing the flow field included in the FoV. The following discussions concern our configuration. With the present optics and distances, the camera FoV of $1200 \times 1600 \mathrm{px}^{2}$ represented a region of about seven $\mathrm{mm}$ by ten $\mathrm{mm}$ in the vertical and horizontal directions, respectively, for the small FoV used in the PTV measurements. Typically, the wall interface was at about 0.2 to $0.5 \mathrm{~mm}$ from the bottom of the image as seen in Figure 3.9a by Skifton [U. Idaho 2015]. (Since the uncertainty in wall-normal location increases with the angle from the optical axis, their Configuration B could be better for near-wall measurements.)

The light sheet thickness was about one to two mm (say two to be conservative). The geometric relationship between the image plane and camera sensors was established by placing a calibration grid vertically along the centerplane $(\mathrm{z}=0)$ of the light sheet and by applying calibration software. Along an inclined light ray drawn through the camera aperture from near the model wall, particles beyond the centerplane from the camera will actually be lower (smaller y) than the intersection with the centerplane so there will be an error in their recorded vertical position, increasing with distance from the centerplane. And the reverse will occur for those closer. (For the present experiment the angle from pinhole to the 
intersection of the light sheet centerplane with the test surface was approximately $\arctan (3.3 \mathrm{~mm} /((12+$ $3 / 4+1 / 2$ in.) $\times 25.4 \mathrm{~mm} / \mathrm{in}$.) $\approx 0.56$ degrees.) Unless the spanwise position is determined somehow, these possible errors will contribute to uncertainties in particle positions, gradients and -- possibly -- velocity components. Cierpka, Scharnowski and Kähler and colleagues [2013; Fuchs et al., 2018] have demonstrated how to apply particle reflections in order to deduce the spanwise position and, from it, an accurate measure of the wall-normal distance.

In contrast to Figure 1 by Cierpka, Scharnowski and Kähler, for an oil channel (as in the present experiment) the light rays pass through three substances with three different refractive indices and --therefore --- three different angles: oil, a glass window and air. These angles and nomenclature are defined in Figure 3. For an off-axis ray, the vertical difference between the position of a particle and its apparent location on the calibration plane (centerline of the light sheet) $\Delta \mathrm{y}_{1}$ can be deduced by applying Snell's Law

$$
\mathrm{n}_{1} \sin \phi_{1}=\mathrm{n}_{2} \sin \phi_{2}=\mathrm{n}_{3} \sin \phi_{3}
$$

Knowing the indices of refraction and the distances $\left(\mathrm{z}_{1}, \mathrm{t}, \mathrm{z}_{2}\right.$ and $\left.\mathrm{y}_{\mathrm{p}}\right)$, one can obtain an exact solution iteratively by choosing trial values of $\phi_{1}$. Alternatively, from a shallow angle approximation and the assumption that $\mathrm{y}_{2}+\mathrm{y}_{3}<<\mathrm{y}_{\mathrm{p}}$, one can deduce

$$
\left(2 \Delta \mathrm{y}_{1} / \Delta \mathrm{z}\right) \approx\left(\mathrm{y}_{\mathrm{p}} / \mathrm{z}_{\mathrm{p}}\right)\left[\left(1-\left(\mathrm{n}_{1} \mathrm{z}_{2} /\left(\mathrm{n}_{2} \mathrm{z}_{1}\right)\right)-\left(\mathrm{n}_{1} \mathrm{z}_{3} /\left(\mathrm{n}_{3} \mathrm{z}_{1}\right)\right)\right) \mathrm{z}_{\mathrm{p}} / \mathrm{z}_{1}\right]
$$

In the brackets the term in parentheses varies in the opposite direction from $\left(\mathrm{z}_{\mathrm{p}} / \mathrm{z}_{1}\right)$ so --- for the geometry of the present study --- $\left(2 \Delta \mathrm{y}_{1} / \Delta \mathrm{z}\right) \approx\left(\mathrm{y}_{\mathrm{p}} / \mathrm{z}_{\mathrm{p}}\right)$ gives a reasonable first approximation. Here we have accounted for the changes in refractive indices for glass and air. However, since their distances are small compared to the thirty $\mathrm{cm}$ in the oil, their effect is only worth a couple per cent of the angle through the laser light sheet. Considering some of the other approximations involved, one probably can neglect their presence in calculating the angle. On the optical axis, the parallax error becomes zero.

Since the particles are distributed randomly in the fluid, this location uncertainty due to parallax contributes to the random uncertainty in location and resulting velocities and gradients.

A comparable analysis gives a random uncertainty in streamwise particle position $\mathrm{x}$ near the left and right edges of the image. For streamwise parallax, one can replace $\mathrm{y}$ with $\mathrm{x}$ in the formulae above. It will contribute to the random uncertainty in individual $u$ measurements and, in conjunction with the local velocity gradients -- $\partial \mathrm{u} / \partial \mathrm{x}$ and $\partial \mathrm{u} / \partial \mathrm{y}$, it will propagate into the uncertainty in mean $\mathrm{U}\{\mathrm{y}\}$. Likewise for mean $\mathrm{V}\{\mathrm{y}\}$.

For the ZPG/TG case, the maximum wall-normal parallax error at the wall was $\Delta \mathrm{y}_{1} \approx 10.2 \mu \mathrm{m} \approx 1.4$ px. One could consider it a worst case uncertainty in the particle position but, since the light intensity varies across the light sheet, the probability of measuring many particles there would be low.

Conceptually, one could perform a sophisticated analysis to generate a reasonable representative random uncertainty for $\mathrm{y}$ (and $\mathrm{x}$ ) accounting for the intensity variation; alternatively, one could pick a value of about one-third of the maximum as an order-of-magnitude guesstimate. In this case that gives an estimated random uncertainty in individual particle position of about one-half px for these optics. It will dominate compared to the uncertainty in particle image center position of $0.05-0.1 \mathrm{px}$ from the PTV algorithm. 


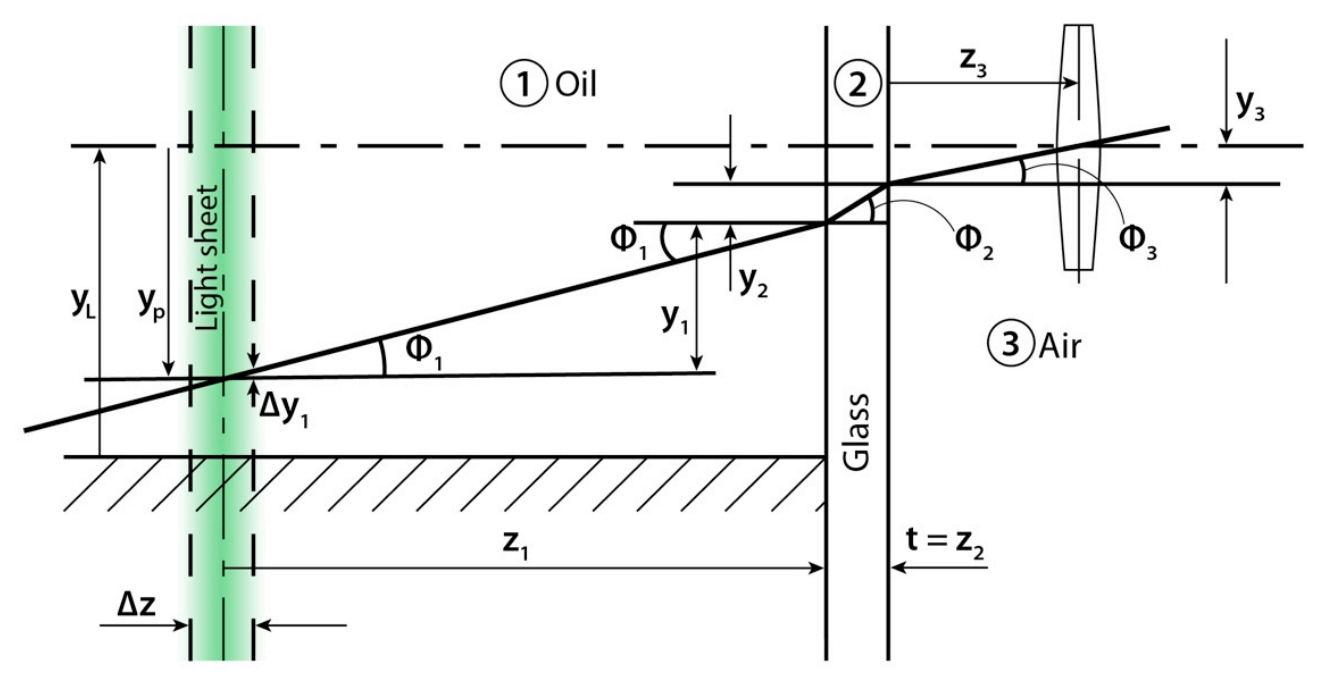

Fig. 3. Geometry of light ray from near wall to PTV camera aperture in the MIR experiments, consistent with Figure 1A by Cierpka, Scharnowski and Kähler [2013]. Not to scale.

For the width, the maximum streamwise parallax error would be $\Delta \mathrm{x}_{1} \approx 15.1 \mu \mathrm{m} \approx 2.4 \mathrm{px}$ at the streamwise FoV edges. These errors $(\Delta \mathrm{x}$ and $\Delta \mathrm{y})$ contribute to uncertainty in deduced particle position and, therefore, gradient calculations. Whether they affect instantaneous velocity results significantly depends on particle location, the displacement and the spanwise motion between the two images of a pair. For some present measurements, maximum parallax shifts in the y direction due to spanwise motion during the time interval between image 1 and image 2 were estimated to be of the order of $0.03 \mathrm{px}$. In the $\mathrm{x}$ direction they could range from zero at the centerline to about fifty per cent more at the streamwise FoV edges. While the mean velocity gradient $\partial \mathrm{U} / \partial \mathrm{x}$ is likely negligible in this developing boundary layer, the derivative of the instantaneous velocity $\partial \mathrm{u} / \partial \mathrm{x}$ can be materially greater [p. 8, Rotta 1962]. The uncertainty in instantaneous $\mathrm{u}$ due to parallax shift during $\Delta \mathrm{t}$ is of the order or smaller than the uncertainty in the PTV algorithm. However, in calculating instantaneous gradients we are comparing this uncertainty in streamwise position of individual particles to the spacing between two (or three) adjacent particles for the denominator of $\Delta \mathrm{u} / \Delta \mathrm{x}$ or $\Delta \mathrm{v} / \Delta \mathrm{x}$. We estimated that the effect on $\Delta \mathrm{x}$ between images 1 and 2 (therefore $\mathrm{u}$ ) would be negligible but $\Delta \mathrm{x}$ between adjacent particles for the gradient requires the parallax uncertainty for each. So we conclude that the uncertainty in instantaneous velocity due to parallax is not significant but resulting uncertainty in position (e.g., $y$ and $\Delta x$ ) can be. It is worth noting that for evaluating indirect entropy generation (or turbulent dissipation of TKE), the most important instantaneous gradient is expected to be $\partial \mathrm{u} / \partial \mathrm{y}$ and its contribution is typically an order-of-magnitude greater than that of $\partial \mathrm{u} / \partial \mathrm{x}$ as shown by Antonia, Kim and Browne [1991; McEligot, Brodkey and Eckelmann, 2009].

One can reduce parallax uncertainty in the streamwise direction by concentrating measurements near the vertical centerline of the image. But, unfortunately, with the current optical configuration uncertainties in wall-normal positions are greatest near the wall region which tends to be of most interest for entropy generation [McEligot et al., 2008]. 


\section{Uncertainty due to vibrations}

Most experimental test sections and/or camera mounts vibrate to some extent. Therefore, the position of the wall relative to the camera moves to some degree from one raw image to the next. This apparent wall displacement will depend on the amplitude and frequency of the vibration. With the coordinate system of a wall shear flow typically related to the wall, errors are introduced in deduced particle coordinates. Various techniques are applied to correct these errors. The uncertainties in these corrections propagate into uncertainties in deduced particle coordinates.

In the present measurements, a commercial "image shift module"/procedure is applied to attempt to shift each image to the same location. A distinctive feature in one image is selected in the wall vicinity to serve as a reference. Then the same feature is identified in other images and they are shifted in $\mathrm{x}$ and $\mathrm{y}$ so that they are located at the same reference location. This process renders a new set of images compared to the very first frame of the set. The feature selected is a bright spot or region in an illuminated band likely caused by particles resting on the horizontal wall surface; the approach of Skifton is described in Section 3.7 of his thesis [2015]. (The illuminated band itself has a thickness of about twenty px [Skifton e-mail 2 Jan 2014]. This width may be due to parallax related to the light sheet thickness plus the apparent sizes of particles in the image.) The uncertainty in the coordinate origin depends on the uncertainty in determining the centroid of the selected feature and possibly position uncertainty due to differing illumination between laser 1 and laser 2. This latter error can be relatively large since alignment is difficult and the intensity profiles of both lasers may differ. However, this error is systematic and should not change randomly. Lacking any better information, as a first estimate we can guess that this coordinate uncertainty is about the same as the uncertainty in the technique for determining individual

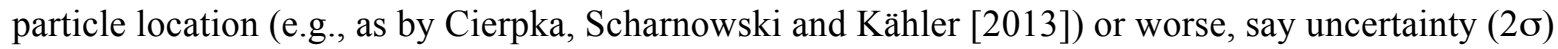
greater than or about $2 \times 0.1 \mathrm{px}$ here. It would be a random uncertainty but, in comparing instantaneous velocities of particles in the same pair of images, the error would be the same for all particles. However, in general, a better approach may be to apply the shift correction later since the rendering of the new images introduces systematic errors (depending on the interpolation method for the new shifted pixel grid) which especially appear with small particle images and in higher order moments.

Thus, to counter vibrations of the test surface and/or optical arrangements, investigators may employ software to shift recorded images so that a distinctive feature in the view is (re)located at a selected reference position, i.e., correcting to the same apparent location for all images. However, there is a danger that the procedure may mistakenly identify a different feature, such as a brighter particle, to adjust to the desired reference position; all particles in that image will be repositioned to erroneous locations (by the same amount $\Delta x, \Delta y)$. In searching, for the cause of a "W-shaped" profile of $U\{y\}$ near the wall in preliminary results of the present experiment, Cierpka [e-mails, 15 Oct 2013, 27 May 2015] found the shift correction was incorrect for 50-125 frames in 4000 sets of images.

Figure 4 demonstrates how the wrongly-shifted frames can affect the location and, hence, the deduced velocity profile. Shown are the instantaneous measurements of streamwise particle displacement for many image sets. The ordinate is the particle displacement during $\Delta \mathrm{t}$ with negative $\Delta \mathrm{x}$ corresponding to positive streamwise velocities. Red circles represent results from improperly shifted frames while small blue diamonds are those with proper frame shifts. The abscissa is the wall-normal distance in pixels; decreasing values translate to distance y increasing from the surface which apparently is in the vicinity of $1070 \mathrm{px}$. Although the matching of the indices of refraction for the oil and quartz conceptually avoids reflections, the particle pattern to the right of about $1080 \mathrm{px}$ indicates that the matching is not always perfect. The incorrectly positioned particle displacements (negative $\Delta \mathrm{x}$ ) identified by the red circles contribute significant velocities to the mean where it should be approximately zero; less obvious improperly-shifted frames to the left of about $1050 \mathrm{px}$ also modify the calculated mean velocities there.

For the current experiment both Cierpka and Skifton developed computer programs to identify and remove the sets of images with improperly-shifted frames. Thus, the number of available views was 
reduced by the order of a hundred sets or about a few per cent. The experimental uncertainty of retaining these improperly-shifted frames depends on a number of factors and is difficult to predict so it is best to remove them.

\section{Duration uncertainty}

For the INL MIR PIV/PTV system, the random uncertainty in the timing is estimated to be about one ns [Anderson, e-mail, 23 March 2006]. For the typical pulse separation of fifty $\mu$ s or more used for the MIR PTV, the uncertainty would be 0.002 per cent or less and, therefore, negligible compared to the measured displacement uncertainty.

\section{Fluid property variation}

The key fluid properties in an MIR experiment are the fluid density, kinematic viscosity and - for optical calculations - the refractive index. These properties were initially measured at the University of Idaho by Orr, Thomson and Budwig [1998] and at INL by McCreery [McIlroy e-mail, 24 August 2006] as

- Density

- Kinematic viscosity

$$
\rho(\mathrm{gm} / \mathrm{mL})=0.8449-0.0005883 \mathrm{~T}+/-0.002
$$

- Refractive index

$$
v(\mathrm{cS})=269.39 \mathrm{~T}^{-0.9366} \quad+/-0.3
$$

where $\mathrm{T}$ is measured in $\mathrm{C}^{\circ}$. During current experiments, operations routinely maintain the matching temperature at $25.156 \mathrm{C} \pm 0.05 \mathrm{C}$; these variations contribute to random uncertainties in measurement series. The related bias uncertainties are about $0.2,2$ and $0.02 \%$ for the calibrations of $\rho, v$ and $n$, respectively. The random uncertainty in kinematic viscosity due to temperature fluctuations of $\pm 0.05 \mathrm{C}$ would be $0.2 \%$.

\section{Calibration uncertainties}

To relate the object FoV to the pixel locations in the camera sensor, a calibration plate was located on the centerplane of the light sheet for the PIV data (large FoV). It had "dot-to-dot" spacing of five mm. For the PTV measurements a $\mu$ PIV calibration plate was used with dot spacing of one mm. The conversion from physical coordinates to pixels was accomplished by the commercial software fitting a third-order polynomial to the calibration data. For the ZPG/TG SFoV used for PTV measurements, the software gave the root-mean-square of the fit as about 0.44 px [Skifton e-mail, 27 May 2015]. Whether this value represents small scale random differences for all individual pixels or gradual variations between the calibration points is not clear (to McEligot). In the latter case, this goodness-of-calibration fit might only indicate how well a cubic or such can fit a group of points not on a nice straight line or a simple smooth curve. This value could be a measure of optical problems from the object plane to the sensor plane as well as non-uniformity of pixel placement and sensitivity. Thus, it might contribute about $0.9 \mathrm{px}$ to the estimation of the random uncertainty $(2 \sigma)$ in determining particle position in an individual image or it might just be a variation over the FoV and be a systematic uncertainty at each individual pixel. In the ZPG/TG experiment at $251 \mathrm{~mm}$, the calibration point spacing of one $\mathrm{mm}$ represents about $140 \mathrm{px}$ while the maximum displacement $\Delta \mathrm{x}$ is about thirty px. Since calibration is accomplished with flow in the test section to maintain the refractive-index-matching temperature, the effects of spatial variations in fluid properties (temperature) and possibly some vibrations will also be included in the calibration uncertainty. 


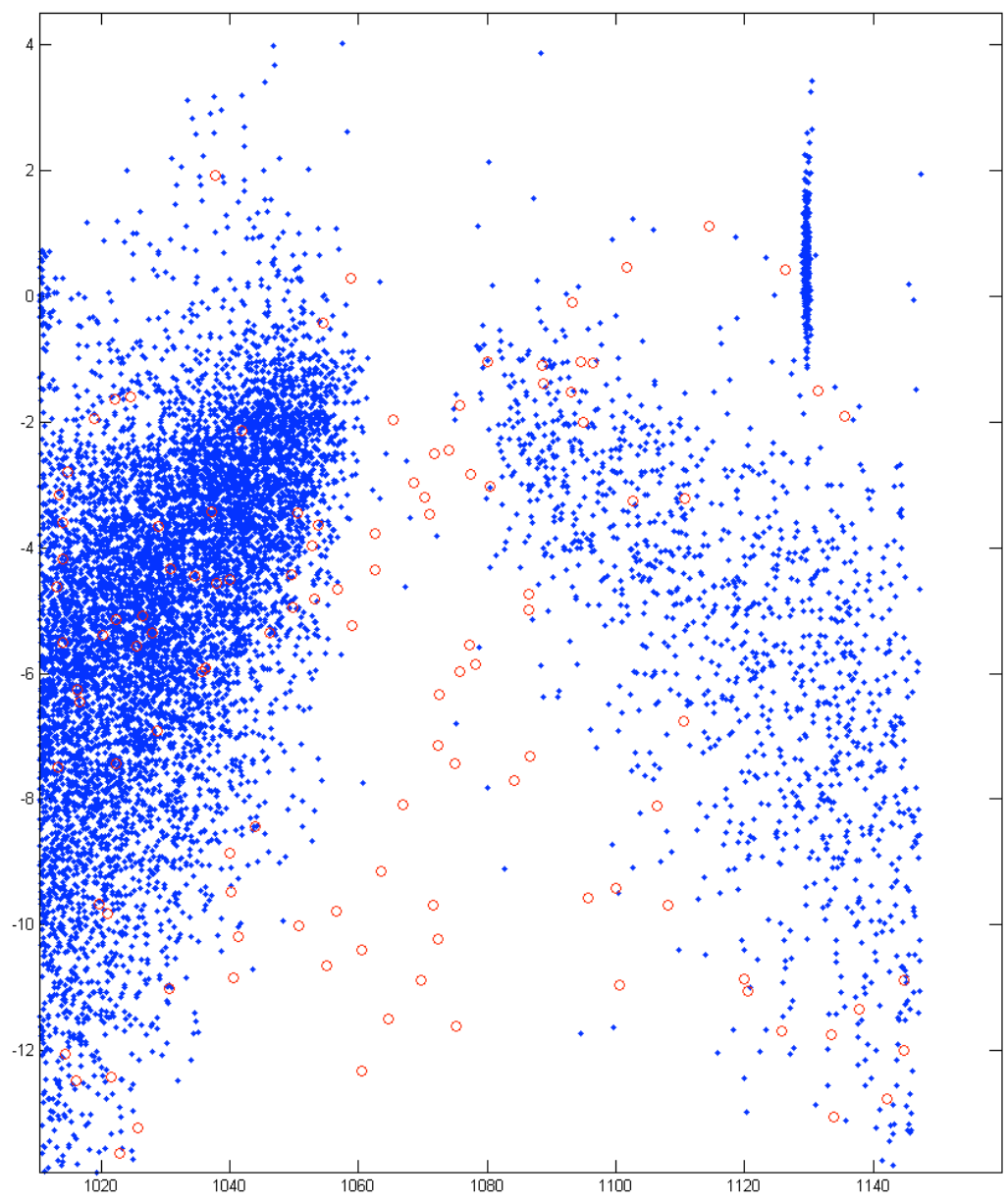

Fig. 4. "Screen shot" of instantaneous streamwise velocity measurements from a number of images with some (red circles) deduced from incorrectly shifted frames. Ordinate is displacement $\Delta \mathrm{x}$ in pixels during interval $\Delta \mathrm{t}$ (therefore proportional to instantaneous streamwise velocity $\mathrm{u}$ ) and abscissa is vertical position y in pixels [Cierpka, e-mail 15 Oct 2013]

In a case such as the INL MIR flow system, which conducts this calibration while in operation, it can be desirable to obtain multiple calibration images. Conceptually, one can then obtain a measure of the effects of some phenomena which simultaneously introduce uncertainties, such as camera and tunnel vibrations, property variations, refractive-index variations, flow rate oscillations and others. Multiple calibrations with the tunnel running with oil and empty without running and with laser 1 and laser 2 separately would be appropriate. The combined results would then be quantified in terms of the temporal variability of the calibration.

\section{MEAN WALL SHEAR STRESS}

To estimate the mean wall shear stress and friction velocity from mean velocity data for experiments on turbulent boundary layers, two approaches are popular: (1) a Clauser plot [1954] in an apparent logarithmic layer and (2) a "linear fit" to points in the near-wall region if resolution permits. Since the spatial resolution of PTV approaches often allows accurate measurements of the mean velocity distribution in the near laminar flow adjacent to the wall [Kähler, Scharnowski and Cierpka, 2012a,b], the 
idea of applying a linear fit to deduce $(\partial \mathrm{U} / \partial \mathrm{y})_{\mathrm{W}}$ can be tempting. (Bradshaw [1971] even refers to the region between the wall and $\mathrm{y}^{+} \approx 5$ as the "linear layer.")

Using the linear fit approximation $\left(\mathrm{U}^{+} \approx \mathrm{y}^{+}\right)$can introduce systematic errors into the deduced mean wall shear stress and apparent wall location.

Two of the problems with applying the linear fit approximation to PTV data are (1) U $\{y\}$ is not linear and (2) the low velocity values near the wall can be highly uncertain (this second problem can also lead to highly uncertain estimates of the particle distances to the wall). Figure 5 demonstrates the first problem. Plotted in the near-wall region are the deviations from the linear fit, $\left(U^{+}\{y\}-y^{+}\right) / y^{+}$, of DNS solutions for developed turbulent boundary layers with streamwise pressure gradients. The results for

FPG are from Spalart [1986] at $\operatorname{Re}_{\theta} \approx 380, \mathrm{~K}_{\mathrm{V}} \approx 2.75 \times 10^{-6}$ and $\mathrm{K}_{\mathrm{p}} \approx-0.020$, a strong negative pressure gradient close to causing laminarization. The ZPG profile is from Schlatter et al. [2009; Schlatter and Örlü, 2010] at $\operatorname{Re}_{\theta} \approx 2400$. The APG predictions come from Spalart and Watmuff [1993] at their $\mathrm{x}=$ $0.95 \mathrm{~m}$ where integral parameters are $\operatorname{Re}_{\theta} \approx 1530, \mathrm{~K}_{\mathrm{V}} \approx-1.20 \times 10^{-6}$ and $\mathrm{K}_{\mathrm{p}} \approx 0.023$, approximately. If one wants to apply a one per cent criterion for agreement with $\mathrm{U}^{+} \approx \mathrm{y}^{+}$, the layer available is very limited, particularly for favorable and negligible pressure gradients.

There are several problems which can lead to uncertain or erroneous measurements near a wall, thereby giving misleading mean velocity profiles and estimates of the "measured" wall shear stress (Figure 6). Some examples are erroneous shift corrections to account for vibrations, interference patterns from illuminated particles on the wall [Kähler, Scholz and Ortmanns, 2006] and parallax due to the thicknesses of the laser light sheets [Cierpka, Scharnowski and Kähler, 2013]. If possible, one needs to estimate the wall-normal distance where these effects are significant --- and avoid fitting mean velocity points in this region --- or correct the errors.

\section{Mean velocity profile}

To represent the total shear stress at a point in a turbulent wall flow, one can write it as

$$
\tau\{\mathrm{y}\}=\mu(\partial \mathrm{U} / \partial \mathrm{y})-\rho \mathrm{u}^{\prime} \mathrm{v}^{\prime}>=\left(\mu+\mu_{\mathrm{t}}\right) \partial \mathrm{U} / \partial \mathrm{y}
$$

where the first term is the contribution of molecular momentum transport and the second comes from turbulent transport. In addition to the effect of turbulent momentum transfer (Reynolds shear stress) increasing as $\mathrm{y}^{+}$increases, so does the effect of streamwise pressure gradient. For a steady turbulent boundary layer, the mean total shear stress profile may be approximated [Rotta, 1962; Finnicum and Hanratty, 1988] as

$$
\left(\tau\left\{\mathrm{y}^{+}\right\} / \tau_{\mathrm{W}}\right) \approx 1+\mathrm{K}_{\mathrm{py}^{+}}-\mathrm{K}_{\mathrm{py}}+\left(\mathrm{C}_{\mathrm{f}} /\left(2 \mathrm{y}^{+}\right)\right) \int_{0}^{\mathrm{y}^{+}}\left(\mathrm{U}^{+}\right)^{2} \mathrm{dy}^{+}
$$

near the surface. The non-dimensional streamwise pressure gradient is defined as $\mathrm{K}_{\mathrm{p}}=\left(\mathrm{v} / \mathrm{\rho u}_{\tau}{ }^{3}\right) \mathrm{dp} / \mathrm{dx}$. The linear approximation is based on the assumption that a constant shear layer, $\tau\{\mathrm{y}\} \approx \tau_{\mathrm{W}}$, occurs near the wall and that the turbulent momentum transport is negligible compared to the molecular transport. Thus the constant shear layer approximation corresponds to a negligible streamwise pressure gradient. Then $\tau_{\mathrm{W}} \approx \mu(\partial \mathrm{U} / \partial \mathrm{y})$ which integrates to $\mathrm{U}^{+} \approx \mathrm{y}^{+}$in wall coordinates. In Figure 5 the deviation seen for ZPG is due to the effect of the turbulent momentum transport becoming observable relative to molecular transport while for FPG and APG the constant shear layer approximation also fails as y increases. 
TBL-DNS-(U-y)/y.qpc

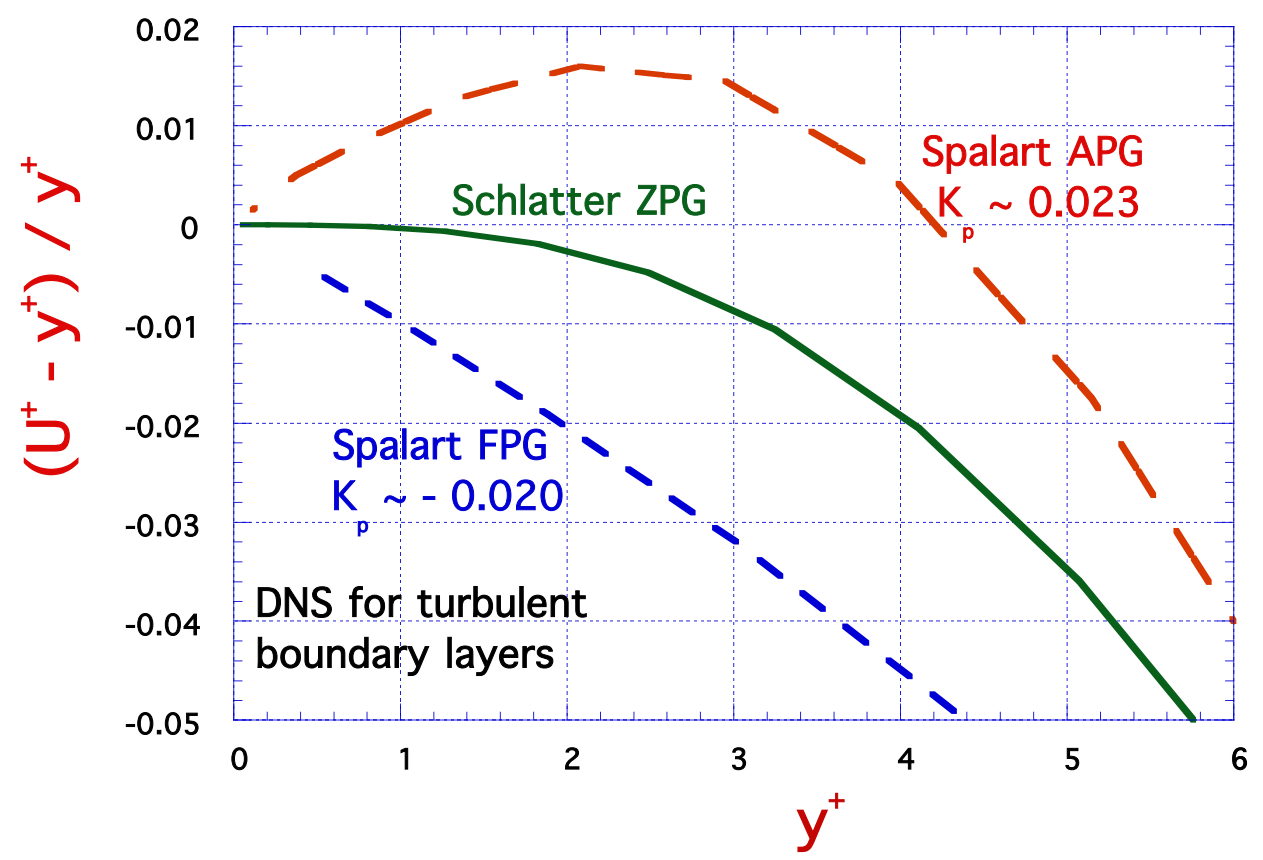

Fig. 5. Deviations from linear fit approximation in near-wall region of developed turbulent boundary layers as predicted with direct numerical simulations.

The lack of linearity has been recognized and treated by a number of investigators. Rotta [1962] explained the variation of turbulent fluctuations $u^{\prime}, v^{\prime}$ and $w^{\prime}$ in the immediate wall region. Some analysts of turbulent wall flows have accounted for turbulent transport for $\mathrm{y}-->0$ in "turbulence models." For example, the popular van Driest mixing length model [1956],

$$
\ell=\kappa \mathrm{y}\left[1-\exp \left(-\mathrm{y}^{+} / 26\right)\right]
$$

is employed to the wall; Bankston and McEligot [1970] successfully used it for strongly-heated gas flow in tubes. McEligot [1985] also applied a version to estimate wall shear stress in the Göttingen Ölkanal from a single measurement of U. Recently at KTH Örlü and colleagues have carefully studied the determination of wall shear stress and the companion importance of the estimate of the position of the wall surface [Örlü, Fransson and Alfredsson, 2010; Alfredsson, Örlü and Schlatter, 2011; Örlü and Vinuesa, 2107; Vinuesa and Örlü, 2017].

Durst et al. [1996] explored the error occurring from fitting $U\{y\}$ linearly or with fourth- and fifthorder polynomials over various intervals $\mathrm{y}_{1}{ }^{+}$to $\mathrm{y}_{2}^{+}$for fully-developed duct flow. They recommend a polynomial to account for the non-linearity. For his experiment Skifton fit a fourth order polynomial to ten to twenty points within $\mathrm{y}^{+}<10$; this approach also provides an improved estimate of the effective wall location and can be applied to deduce the pressure-gradient parameter $\mathrm{K}_{\mathrm{p}}$ [Skifton et al., 2017]. 


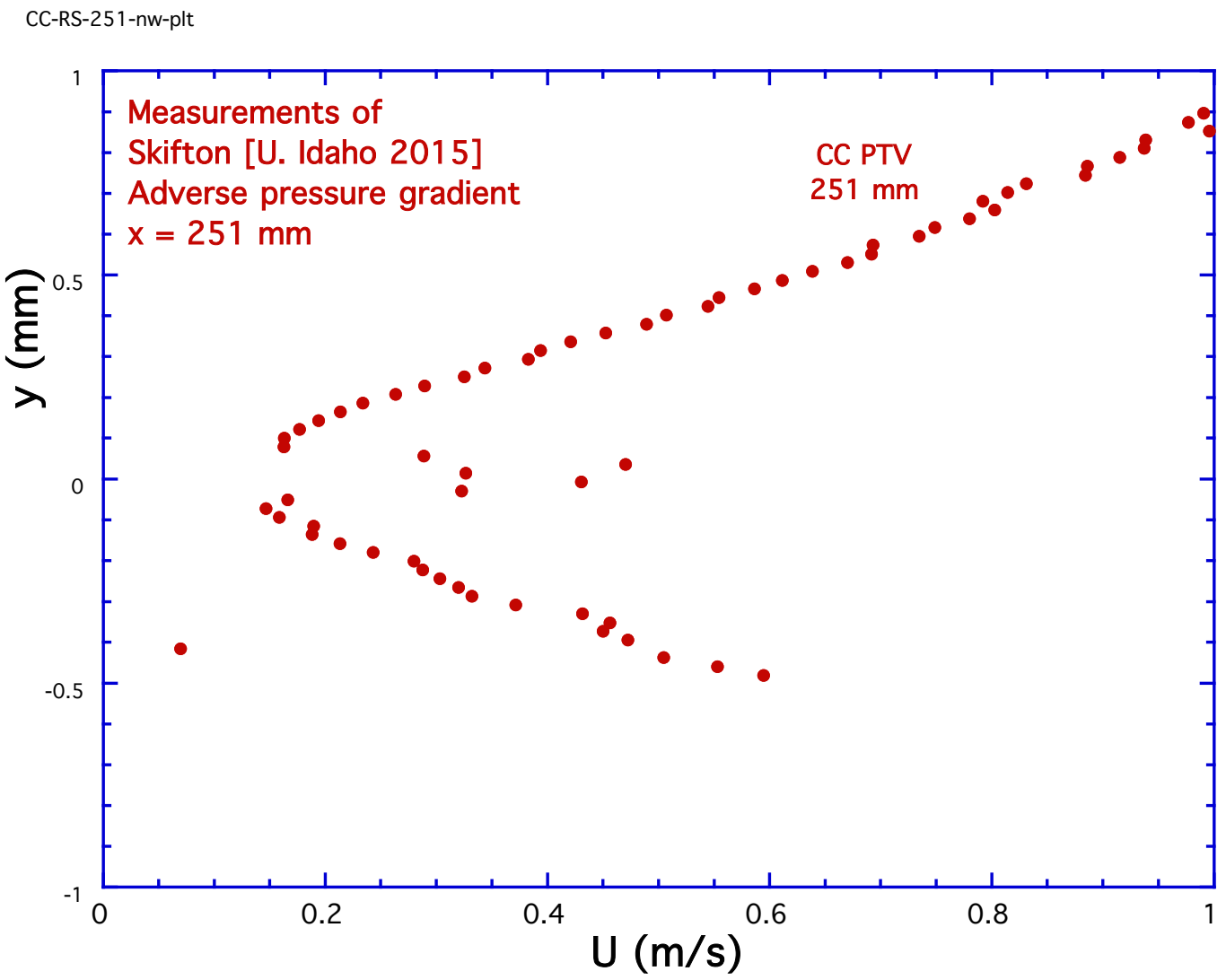

Fig. 6. Preliminary results of mean streamwise velocity measurements in near-wall region by particle tracking velocimetry [Skifton, 2015].

\section{Near-wall problems}

To counter vibrations of the test surface and/or optical arrangements, investigators may employ software to shift recorded images so that a distinctive feature in the view is (re)located at a selected reference position, i.e., correcting to the same apparent location for all images, as discussed in the section on "Uncertainty due to vibrations.) As mentioned, there is a danger that the procedure may mistakenly identify a different feature, such as a brighter particle, to adjust to the desired reference position; all particles in that image will be repositioned to erroneous locations (by the same amount $\Delta x, \Delta y$ ). Figure 4 demonstrates how the wrongly-shifted frames can affect the location and, hence, the deduced velocity profile. In searching, for the cause of a "W-shaped" profile of $U\{y\}$ near the wall in preliminary results of the present experiment, Cierpka [e-mails, 15 Oct 2013, 27 May 2015] found the shift correction was incorrect for 50-125 frames in 4000 sets of images. The incorrectly positioned particle displacements (negative $\Delta \mathrm{x}$ ) identified by the red circles in Figure 4 contribute significant velocities to the mean where it should be approximately zero. For the current experiment both Cierpka and Skifton developed computer programs to identify and remove the sets of images with improperly-shifted frames.

Kähler, Scholz and Ortmanns [2006] demonstrated how interference patterns from illuminated particles can also cause a "W-shaped" mean velocity profile near the wall (their Figures 12 and 13). They interpret the center peak in the "W" as the wall location. For their optical arrangement and working fluid of air, they concluded that their biased data points were in the region $\mathrm{y}<\sim 20 \mu \mathrm{m}$ and these points must be removed for accurate estimates of wall shear stress. 
The importance of parallax in 2-D PIV and PTV systems has been examined by Cierpka, Scharnowski and Kähler [2013]. They treated three optical arrangements used near a surface. Of these, the present experiments employed Configuration A in Figure 1 of Cierpka, Scharnowski and Kähler, thereby maximizing the flow field included in the FoV. The light sheet thickness was about one to two $\mathrm{mm}$ (say two to be conservative). Since the test surface is horizontal and facing upward with vertical light sheets in the present experiment, "heavy" particles can settle on it so that there may be significant numbers of zero and near-zero velocity particles illuminated on the surface.

The geometric relationship between the image plane and camera sensors was established by placing a calibration grid vertically along the centerplane $(\mathrm{z}=0)$ of the light sheet and by applying calibration software. Along an inclined light ray drawn through the camera aperture from near the model wall, as in Figure 7, particles beyond the vertical light sheet centerplane will actually be lower (smaller y) than the intersection with the centerplane (taken as the wall-normal coordinate y) so there will be an error in their recorded vertical position, increasing with distance from the centerplane. And the reverse will occur for those closer than the centerplane. Unless the spanwise position is determined somehow, these possible errors will contribute to uncertainties in particle positions, gradients and -- possibly -- velocity components.

As shown in Figure 7, when a "ray" from a particle is far enough away from the wall that it does not intercept the wall where it is lit by the light sheet, then --- as a first approximation --- the errors in apparent instantaneous velocity due to particles on opposite sides of the light sheet probably mostly balance each other giving a reasonable estimate of the mean velocity at the center position of the light sheet (point 2). There may be a slight bias due to the number of particles increasing with distance from the wall -- as the average velocity also does.

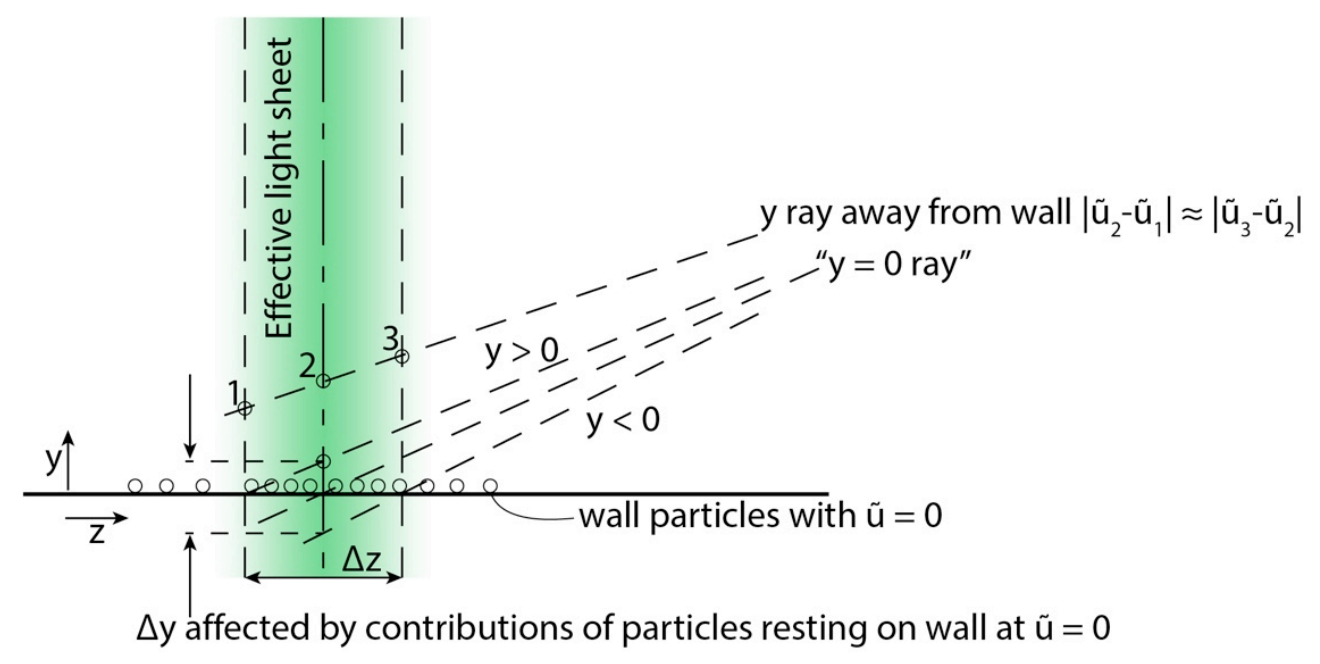

Fig. 7. "Parallax" geometry of near-wall measurements by particle tracking velocimetry with laser light sheets of finite thickness $\Delta \mathrm{z}$ and optical arrangement $\mathrm{A}$ from Figure 1 of Cierpka, Scharnowski and Kähler [2013]. 
When a ray intercepts the wall within the light sheet, there may be a strong contribution of zero or near-zero velocity from particles on the wall (if the PTV procedure can identify individual wall particles in the successive images of a pair). This contribution would then be averaged with moving particles along the ray within the light sheet.

When a ray strikes the wall on the far side of the light sheet so its position is identified as $y>0$ along the centerplane (e.g., y $>0$ in Figure 7) some of the balancing, lower-velocity particles are eliminated or possibly replaced by higher-velocity particles from reflections. However, any particles along the ray and nearer to the camera than the centerplane would provide their full values to the calculation of the mean velocity. Thus, the estimated mean velocity will be biased towards the higher velocities of particles measured along the ray in the half of the light sheet towards the camera. While there may be slight deviations from the correct mean for $\mathrm{U}\{\mathrm{y}\}$ when the pertinent viewing rays do not intersect the wall within the light sheet, one can expect the effect and resulting deviation to become greater when they do (between rays $\mathrm{y}>0$ and $\mathrm{y}=0$ in Figure 7).

A result of this behavior near the wall is that parallax in the present optical configuration will lead to the calculation of higher mean velocities than the correct $U\left\{y, z_{\text {light sheet }\}}\right\}$ as the wall is approached. The onset of this effect may appear as a point of inflection in a plot of the "measured" mean velocity profile.

\section{An approach}

The "measured" mean velocities for the near-wall region --- after Cierpka removed the incorrectlyshifted frames --- are presented in Figure 8 for the same data as in Figure 6 where the incorrectly-shifted frames have been included. These data are at $\mathrm{x}$ about $251.1 \mathrm{~mm}$ for the APG experiment; at this location the flow is believed to be a developed turbulent boundary layer slightly beyond transition. Some integral parameters at this location are $\delta \approx 11.2 \mathrm{~mm}, \theta \approx 1.33 \mathrm{~mm}, \mathrm{H}_{1,2} \approx 1.80, \mathrm{Re}_{\ominus} \approx 260.6, \mathrm{~K}_{\mathrm{v}} \approx-1.57 \times 10^{-6}$ and $\mathrm{K}_{\mathrm{p}} \approx 0.00973$, deduced in conjunction with the LFoV PIV results of Skifton.

With the aid of a straight edge, one can see that this profile is not quite linear. Also an inflection point is evident around $\mathrm{y} \approx 0.14 \mathrm{~mm}$ and $\mathrm{U} \approx 0.20 \mathrm{~m} / \mathrm{s}$ with the apparent $\mathrm{U}$ becoming higher than the extrapolation from larger $y$.

To approximate these velocity data, one of the authors fit a quadratic curve through three "representative" points outside the inflection point, i.e., $\mathrm{y} \approx 0.16,0.29$ and $0.49 \mathrm{~mm}$, corresponding to $\mathrm{y}^{+} \approx$ 1.6, 3.0 and 5.1, respectively. More sophisticated approaches could be applied, maybe cubic or Skifton's fourth-order least-squares fit, but Figure 8 seems to show reasonable agreement with the present approach. Important in any approach is avoiding the incorrect data points near the wall.

The fitted quadratic intercepts the ordinate $U=0$ at about $0.00992 \mathrm{~mm}$, giving an improved estimate of the effective wall location. The deduced gradient $(\partial \mathrm{U} / \partial \mathrm{y})_{\text {wall }}$ is $15131 / \mathrm{sec}$ which converts to a friction velocity $\mathrm{u}_{\tau} \approx 0.142 \mathrm{~m} / \mathrm{s}$ and 0.00594 for the skin friction coefficient. For the estimated Reynolds number, $\operatorname{Re}_{\Theta} \approx 260.6$, the correlation by Smits, Matheson and Joubert [1983] gives 0.00597 , about 1/2 per cent difference. This correlation has been recommended by Schlatter et al. [2009] for turbulent boundary layers with negligible pressure gradients. Since the present adverse pressure gradient might be considered to be moderate at $\mathrm{x}=251 \mathrm{~mm}$, this agreement can be taken to be an encouraging sign. 


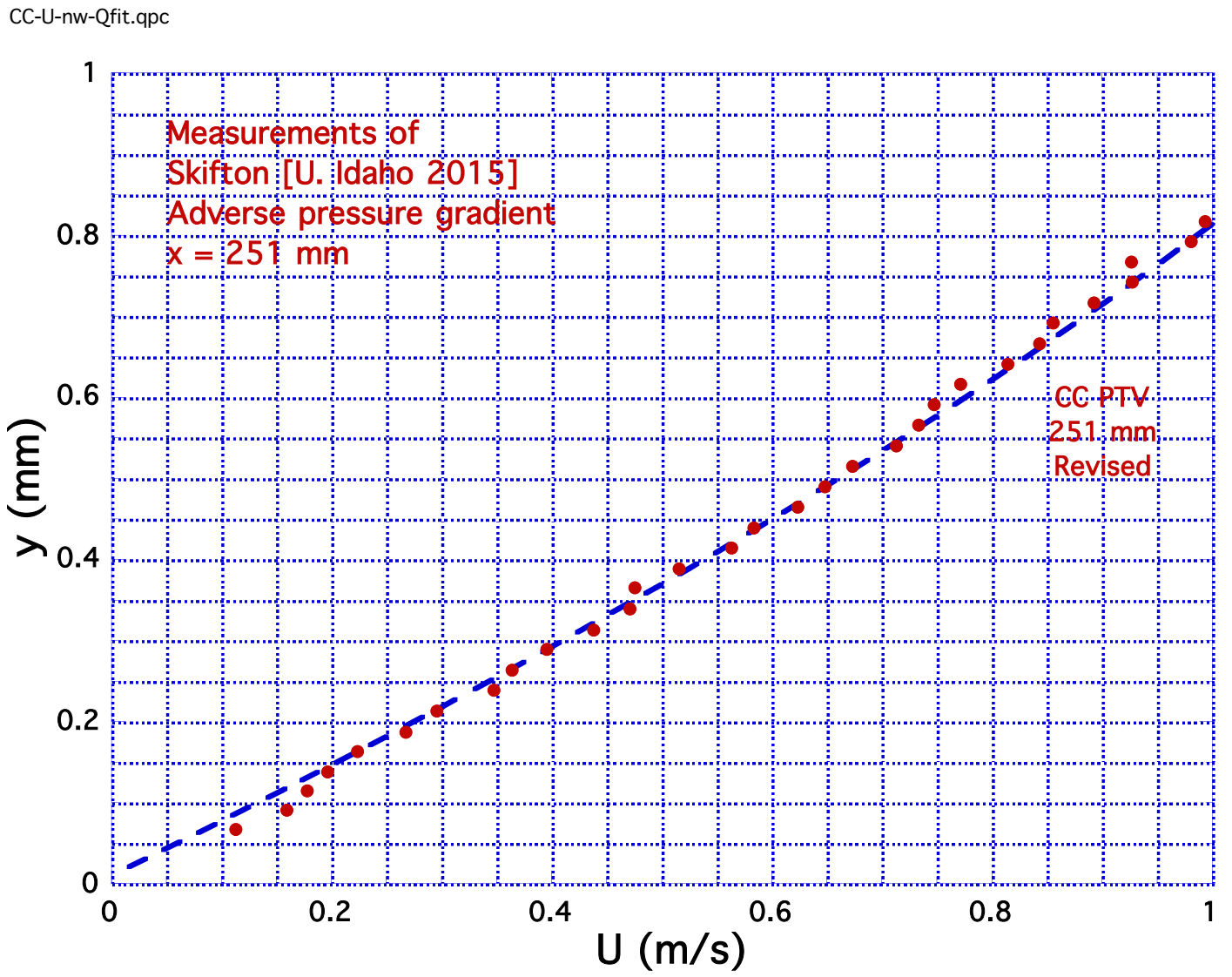

Fig. 8. Near-wall measurements of Skifton [2015] analysed with PTV data acquisition code of Cierpka [Uni. der Bundeswehr, 16 October 2013]. Data = circles, quadratic fit $=$ dashed curve.

\section{CONCLUDING REMARKS}

In turbulent wall shear flows, such as a boundary layer, entropy generation is typically concentrated near the wall [Rotta, 1962; McEligot et al., 2008]. As shown by Equation 1, evaluation of the pointwise entropy generation rate involves determination of the instantaneous gradients of the three velocity components. In the present case. particle tracking velocimetry is used to measure the instantaneous velocity components in the near-wall region so aspects of such measurements are examined.

Review of expected shear layer sizes indicates that the most restrictive spatial resolution required could require particle spacing of the order of $\Delta \mathrm{x}^{+}$(or $\Delta \mathrm{z}^{+}$) about 0.6 or 0.4 using a quadratic or cubic fit to treat the narrowest shear layer. As an example of the spatial resolution of PTV measurements with the oil tunnel of the INL MIR flow system, for the NPG experiment with turbulence generator at $\mathrm{x} \approx 271 \mathrm{~mm}$, the particle seeding typically is $\mathrm{N}_{\mathrm{ppp}} \approx 0.005 \mathrm{ppp}$ [Skifton e-mail $7 \mathrm{Jul} 2015$ ] and the physical size is given by about $0.00722 \mathrm{~mm} / \mathrm{px}$. The mean particle image spacing can be estimated as $\Delta \mathrm{x} \approx\left(\mathrm{N}_{\mathrm{X}}\right.$ $\left.\mathrm{N}_{\mathrm{y}} / \mathrm{N}_{\mathrm{p}}\right)^{1 / 2} \approx\left(1 / \mathrm{N}_{\mathrm{ppp}}\right)^{1 / 2}$ [Cierpka, Lütke and Kähler, 2013] or about fourteen px in this case. This value converts to $\Delta \mathrm{x}^{+} \approx 0.6$ at this location. However, not all particles provide meaningful velocity vectors as discussed in their Section 1.3 by Cierpka, Lütke and Kähler. 
For a typical pair of images at this location, Skifton found about 3850 valid vectors across a grid of $1074 \times 1600 \mathrm{px}^{2}$ for an average vector spacing $\Delta \mathrm{r}_{\mathrm{vec}}$ of about $21.1 \mathrm{px}$ or about 0.9 in wall coordinates. Cierpka, Lütke and Kähler studied potential improvements in PTV techniques. They note that Lei et al. [2012] claimed they could detect particle image centers (i.e., particle locations) with particle image overlap as high as fifty per cent. Figure 1 by Cierpka, Lütke and Kähler shows particle image overlap as functions of particle concentration and spacing; for spacing $L \approx 3 \mathrm{px}$, limiting overlap to twenty per cent would require concentrations of about 0.018 or less, corresponding to average particle spacing of $\Delta \mathrm{x}^{+} \approx$ 0.3 at $\mathrm{x} \approx 271 \mathrm{~mm}$.

Here we have been considering average particle spacing. In any image some particles will be closer to one another and others will be further than the average. So somewhat better resolution could be possible if one screens for an appropriate threshold of spacing in calculating gradients. Thus, it appears feasible to obtain seeding for PTV in the INL MIR system adequate to satisfy the stringent resolution possibly desired while it is unlikely to be possible with PIV correlation techniques.

Some experimental uncertainties were estimated. Idealized analytic predictions of PTV algorithms lead to estimates of the random uncertainties $(2 \sigma)$ in particle displacement between a pair of images as being about 0.1 to $0.3 \mathrm{px}$ (of the studies considered, only Theunissen, Stitou and Riethmuller [2004] addressed systematic uncertainties, estimating about 0.4 to $0.8 \mathrm{px}$ ). Other sources of uncertainties considered included camera quality, parallax, vibrations, timing between laser pulses, fluid property variation and calibration. The calibration uncertainty may encompass a number of phenomena, such as optical paths, spatial variation of fluid properties (temperature), pixel placement and sensitivity and possibly vibration. For the present experiment the calibration uncertainty contributed about $0.9 \mathrm{px}$ to the random uncertainty of a particle position in an individual image (or about $1.4 \times 0.9 \mathrm{px}$ to the displacement between a pair of images).

Estimation of the mean wall shear stress from mean velocity measurements by PTV in the near-wall region is discussed. Since the velocity profile is not exactly linear, a polynomial approximation is more desirable than the popular "linear fit" to determine the velocity gradient at the wall. Near-wall problems, such as parallax and possible interference patterns from wall particles, can lead to erroneous velocity determination in the immediate wall region and should be avoided in the fitting procedure.

Some additional considerations that have not been addressed herein include "loss of pairs" effects, misidentified particles, possible uncertainties in instantaneous velocities and profiles related to the range of parallax and accurate conversion of randomly-located instantaneous particle velocity distributions to useful regular grids for further processing. These topics warrant study to determine whether they may be significant problems.

An earlier report addressed uncertainties related to particle image velocimetry (PIV) measurements also in the oil tunnel of the INL MIR flow system [McEligot, McIlroy and Johnson, INL/EXT-07-13539]. It treated experimental uncertainties in general, PIV uncertainty analyses, particle motion, velocity uncertainties, positioning uncertainties and uncertainties in fluid properties, geometry, flow rates and Reynolds number, some of which can be of interest in the context of the present study.

\section{ACKNOWLEDGEMENTS}

We thank Prof. Dr. Christian J. Kähler and his colleagues at Institut für Strömungsmechanik und Aerodynamik, Universität der Bundeswehr München, for their gracious hospitality and technical support during part of the writing of this report. In particular, gratitude is due to Dr. rer. nat. Sven Scharnowski for his assistance with insight into PIV/PTV uncertainties and his development of parallax analyses and to Dr.-Ing. Rainer Hain for his study of camera quality. This study was partly supported financially by the U.S. DoE Experimental Program to Stimulate Competitive Research under Award DE-SC0004751 and by the Center for Advanced Energy Studies via U.S. Department of Energy Idaho Operations Office Contract 
DE-AC07-05ID14517. Accordingly, the U.S. Government and its representatives retain a nonexclusive, royalty-free license to publish or reproduce the published form of this contribution, or allow others to do so, for U.S. Government purposes.

\section{REFERENCES}

Abernathy, R. B., R. P. Benedict and R. B. Dowdell, 1989. ASME measurement uncertainty. J. Fluids Eng., 107, pp. 161-164.

Adrian, R. J., and J. Westerweel, 2011. Particle image velocimetry. Cambridge: Univ. Press.

Alfredsson, P. H., R. Örlü and P. Schlattter, 2011. The viscous sublayer revisited - exploiting selfsimilarity to determine the wall position and friction velocity. Exp. Fluids, 51, pp. 271-280.

Allain, R., 2019. Measurement and uncertainty notes. Southeastern Louisiana U., www2.southeastern.edu/Academics/Faculty/rallain/plab194/error.html accessed 29 March.

Anderson, S., 2006. Personal electronic communication. laVision, Inc., Ypsilanti, Mich., 23 March. Anderson, S., 2019. Personal electronic communication. laVision, Inc., Ypsilanti, Mich., 25 April.

Antonia, R. A., J. Kim and L. W. B. Browne, 1991. Some characteristics of small-scale turbulence in a turbulent duct flow. J. Fluid Mech., 233, pp. 369-388.

Bankston, C. A., and D. M. McEligot, 1970. Turbulent and laminar heat transfer to gases with varying properties in the entry region of circular ducts. Int. J. Heat Mass Transfer, 13, pp. 319-344.

Blackwelder, R. F., and H. Eckelmann, 1979. Streamwise vortices associated with the bursting phenomenon. J. Fluid Mech., 94, pp. 577-594.

Budwig, R. S., and R. Westin, 2011. Measurements of oil properties. Informal technical report, U. Idaho, Boise, Ida.

Bradshaw, P., 1971. An introduction to turbulence and its measurement. Oxford: Pergamon.

Cierpka, C., 2013. Personal electronic communication. Uni. der Bundewehr, München, 29 August.

Cierpka, C., 2013. Personal electronic communication. Uni. der Bundewehr, München, 15 October.

Cierpka, C., 2013. Personal electronic communication. Uni. der Bundewehr, München, 16 October.

Cierpka, C., 2015. Personal electronic communication. Uni. der Bundewehr, München, 27 May.

Cierpka, C., 2015. Personal electronic communication. Uni. der Bundewehr, München, 16 October.

Cierpka, C., 2019. Personal electronic communication. Tech. Uni. Ilmenau, Ilmenau, 2 April.

Cierpka, C., 2019. Personal electronic communication. Tech. Uni. Ilmenau, Ilmenau, 16 May.

Cierpka, C., and C. J. Kähler, 2012. Cross-correlation or tracking -- Comparison and discussion. Proc., 16th Int. Symp. Appl. Laser Tech. Fluid Mech., Lisbon.

Cierpka, C., B. Lütke and C. J. Kähler, 2013. Higher order multi-frame particle tracking velocimetry. Exp. Fluids, 54, pp. 1533-1 to -12 .

Cierpka, C., S. Scharnowski and C. J. Kähler, 2013. Parallax correction for precise near-wall flow investigations using particle imaging. Appl. Optics, 52 (No. 12), pp. 2923-2931.

Clauser, F. H., 1954. Turbulent boundary layers in adverse pressure gradients. J. Aeronaut. Sci., 21, pp. 91-108.

Corino, E. R., and R. S. Brodkey, 1969. A visual observation of the wall region in turbulent flow. J. Fluid Mech., 37, pp. 1-30. 
Durst, F., H. Kikura, I. Lekakis, J. Jovanovic and Q. Ye, 1996. Wall shear stress determination from near-wall mean velocity data in turbulent pipe and channel flows. Exp. Fluids, 20. pp. 417-428.

Finnicum, D. S., and T. J. Hanratty, 1988. Effect of favourable pressure gradients on turbulent boundary layers. AIChE J., 34, pp. 529-540.

Fuchs, T., M. Bross, S. Scharnowski and C. J. Kähler, 2018. Parallax corrected PTV for precise near wall boundary layer measurements. Proc., 19th Int. Symp. Appl. Laser and Imaging Tech. Fluid Mech., Lisbon, 16-19 July.

Hain, R., 2015. Personal electronic communication. Uni. der Bundewehr, München, 20 November.

Hain, R., C. J. Kähler and C. Tropea, 2007. Comparison of CCD, CMOS and intensified cameras. Exp. Fluids, 42, pp. 403-411.

Kähler, C. J., 2004. Investigation of the spatio-temporal structure in the buffer region of a turbulent boundary layer by means of multiplane stereo PIV. Exp. Fluids, 36, pp. 114-130.

Kähler, C. J., U. Scholz and J. Ortmanns, 2006. Wall-shear stress and near-wall turbulence measurements up to single pixel resolution by means of long-distance micro-PIV. Exp. Fluids, 41, pp. 327-341.

Kähler, C. J., S. Scharnowski and C. Cierpka 2012a. On the resolution limit of digital particle image velocimetry. Exp. Fluids, 52, pp. 1629-1639.

Kähler, C. J., S. Scharnowski and C. Cierpka 2012b. On the uncertainty of digital PIV and PTV near walls. .Exp. Fluids, 52, pp. 1644-1656.

Kim, J. H., T. W. Simon and R. Viskanta, 1993. Journal of Heat Transfer policy on reporting uncertainties in experimental measurements and results. J. Heat Transfer, 115, pp. 5-6.

Kline, S. J., 1985. The purposes of uncertainty analysis. J. Fluids Eng., 107, pp. 153-160.

Kline, S. J., and F. A. McClintock, 1955. Describing uncertainties in single-sample experiments. Mech. Eng., 75, (Jan.). pp. 3-8.

Lassahn, G. D., 1985. Uncertainty definition. J. Fluids Eng., 107, p. 179.

Lei, Y. C., W. H. Tien, J. Duncan, M. Paul, N. Ponchaut, C. Mouton, D. Dabiri, T. Rösgen and J. Hove, 2012. A vision-based hybrid particle tracking velocimetry (PTV) technique using a modified cascade correlation peak-finding method. Exp. Fluids, 53, pp. 1251-1268.

Lin, J., J. P. Laval, J. M. Foucaut and M. Stanislas, 2008. Quantitative characterization of coherent structures in the buffer layer of near-wall turbulence. Part 1: streaks. Exp. Fluids, 45, pp. 999-1013.

McCreery, G. E., 2011. Particle Tracking Velocimeter - description, applications and operation. Draft informal technical report, Mech. Engr. Dept., Idaho State U., 4 December. Available from gem@srv.net.

McEligot, D. M., 1985. Measurement of wall shear stress in favorable pressure gradients. Lec. Notes Physics, 235, pp. 292-303.

McEligot, D. M., R. S. Brodkey and H. Eckelmann, 2009. Laterally converging duct flows: Part 4. Temporal behavior in the viscous layer. J. Fluid Mech., 634, pp. 433-461.

McEligot, D. M., and H. Eckelmann, 2006. Laterally converging duct flows: Part 3. Mean turbulence structure in the viscous layer. J. Fluid Mech., 549, pp. 25-59.

McEligot, D. M., H. M. McIlroy and R. C. Johnson, 2007. Estimated uncertainties in Idaho National Laboratory matched-index-of-refraction lower plenum experiment. Technical report INL/EXT-07-13539, November. Available from U. S. DoE Office of Scientific and Technical Information (OSTI) as www.osti.gov/servlets/purl/924503. 
McEligot, D. M., K. P. Nolan, E. J. Walsh and E. Laurien, 2008. Effect of pressure gradients on entropy generation in the viscous layers of turbulent wall flows. Int. J. Heat Mass Transfer, 51, pp. 1104-1114.

McEligot, D. M., E. J. Walsh, E. Laurien and P. R. Spalart, 2008. Entropy generation in the viscous parts of a turbulent boundary layer. J. Fluids Engr., 130, pp. 061205-1 to -12.

McIlroy, H. M., 2006. Personal electronic communication, 24 August.

McIlroy, H. M., S. Becker and D. M. McEligot, 2011. Large Matched-Index-of-Refraction (MIR) flow systems for thermal engineering education. Innovations 2011 World Innovations in Engineering Education and Research (Ed.: W. Aung et al.), Potomac, Md.: International Network for Engineering Education and Research, Ch. 6, pp. 69-87.

McIlroy, H. M., and R. S. Budwig, 2007. The boundary layer over turbine blade models with realistic rough surfaces. J. Turbomachinery, 129, pp. 318-330.

Moffat, R. J., 1982. Contributions to the theory of single-sample uncertainty analysis. J. Fluids Eng., 104. pp. 250-260.

Moffat, R. J., 1988. Describing the uncertainties in experimental results. Exp. Thermal Fluid Sci., 1, pp. 3-17.

NDT Resource Center, 2014. Accuracy, error, precision and uncertainty. NDT Resource Center, Iowa State U., www.nde-ed.org/GeneralResources/ErrorAnalysis/UncertaintyTerms.htm accessed 29 March 2019.

Neilson, W. A. (Ed.), 1959. Webster's new international dictionary of the English language, 2nd ed. Springfield: G. \& C. Merriam.

NIST, 2019. The NIST reference on constants, units and uncertainty. Physical Measurement Lab., NIST., physics.nist.gov/cuu/Uncertainty/index.html accessed 29 March.

Nolan, K. P., and T. A. Zaki, 2013. Conditional sampling of transitional boundary layers in pressure gradients. J. Fluid Mech., 728, pp. 306-339.

Örlü, R., J. H. M. Fransson and P. H. Alfredsson, 2010. On near wall measurements of wall bounded flows - the necessity of an accurate determination of the wall position. Prog. Aero. Sci.. 46, pp. 353387.

Örlü, R., and R. Vinuesa, 2017. Thermal anemometry. Experimental Aerodynamics (Ed.: S. Discetti and A. Ianiro). CRC Press, Ch. 9, pp. 284-291.

Orr, B., E. Thomson and R. S. Budwig, 1997. Drakeol 5 thermophysical property measurements. Mech. Engr. Dept., U. Idaho, Moscow, 18 December.

Raffel, M., C. Willert, S. Wereley and J. Kompenhans, 2007. Particle image velocimetry, a practical guide, 2nd ed. Berlin: Springer.

Raffel, M., C. E. Willert, F. Scarano, C. J. Kähler, S. T. Wereley and J. Kompenhans, 2018. Particle image velocimetry, a practical guide, 3rd ed. Berlin: Springer.

Rotta, J. C., 1962. Turbulent boundary layers in incompressible flow. Prog. Aero. Sci., 2, pp. 1-219.

Scharnowski, S., M. Bross and C. J. Kähler, 2019. Accurate turbulence level estimates using PIV/PTV. Exp. Fluids, 60, No. 1, 12 pgs. doi.org/10.1007/s00348-018-2646-5.

Schlatter P., and R. Örlü, 2010. Assessment of direct numerical simulation data of turbulent boundary layers. J. Fluid Mech., 659, pp. 116-126. 
Schlatter, P., R. Örlü, Q. Li, G. Brethouwer, J. H. M. Fransson, A. V. Johansson, P. H. Alfredsson and D. S. Henningson, 2009. Turbulent boundary layers up to $\operatorname{Re}_{\Theta}=2500$ studied through simulation and experiment. Phys. Fluids, 21, pp. 051702-1 to -4 .

Schlichting, H., and K. Gersten, 2000. Boundary layer theory, $8^{\text {th }}$ revised and enlarged edition. Berlin: Springer.

SERC, 2019. What is measurement and uncertainty? Science Education Research Center, Carleton U., serc.carleton.edu/sp/library/uncertainty/what.html accessed 29 March.

Skifton, R. S., 2014. Personal electronic communication. U. Idaho, 2 January.

Skifton, R. S., 2015. Personal electronic communication. U. Idaho, 27 May.

Skifton, R. S., 2015. Personal electronic communication. U. Idaho, 7 July.

Skifton, R. S., 2015. Entropy generation for a bypass transitional boundary layer and improved particle image velocimetry measurement using the particle density information. Ph.D. thesis, U. Idaho.

Skifton, R. S., R. S. Budwig, J. C. Crepeau and T. Xing, 2017. Entropy generation for bypass transitional boundary layers. J. Fluids Engr., 139, pp. 041203-1 to -13.

Smith, B. L., 2019. Personal electronic communication. Utah State U., 26 April.

Smits, A. J., N. Matheson and P. N. Joubert, 1983. Low Reynolds number turbulent boundary layers in zero and favourable pressure gradients. J. Ship Res., 127, pp. 147-157.

Spalart, P. R., 1986. Numerical study of sink-flow boundary layers. J. Fluid Mech., 172, pp. 307-328.

Spalart, P. R., and J. H. Watmuff, 1993. Experimental and numerical study of a turbulent boundary layer with pressure gradients. J. Fluid Mech., 249, pp. 337-371.

Stanislas, M., K. Okamoto, C. J. Kähler and J. Westerweel, 2005. Main results of the Second International PIV Challenge. Exp. Fluids, 39, pp. 170-191.

Stitou A., and M. L. Riethmuller, 2001, Extension of PIV to super resolution using PTV, Meas. Sci. Tech., 12, pp. 1398-1403.

Stoots, C. M., S. Becker, K. G. Condie, F. Durst and D. M. McEligot, 2001. A large-scale matchedindex-of-refraction flow facility for LDA studies of complex geometries. Exp. Fluids, 30, pp. 391-398, 2001.

Taylor, J. R., 1997. An introduction to error analysis: The study of uncertainties in physical measurements, 2nd ed. Sausalito: Univ. Science Books.

Theunissen, R., A. Stitou and M. L. Riethmuller, 2004. A novel approach to improve the accuracy of PTV methods. Paper 27.1, 12th Int. Symp. Appl. Laser Tech. Fluid Mech., Lisbon.

Thwaites, B, 1949. Approximate calculation of the laminar boundary layer. Aero. Quarterly, 1, pp. 245280.

van Driest, E. R., 1956. On turbulent flow near a wall. J. Aeronaut. Sci., 23, pp. 1007-1011 and 1036.

Vinuesa, R., and R. Örlü, 2017. Measurement of wall shear stress. Experimental Aerodynamics (Ed.: S. Discetti and A. Ianiro). CRC Press, Ch. 12, pp. 393-428.

Walsh, E. J., D. M. McEligot, L. Brandt and P. Schlatter, 2011. Entropy generation in boundary layers transitioning under the influence of freestream turbulence. J. Fluids Engr., 133, pp. 061203-1 to -10.

Wieneke, B., and A. Sciacchitano, 2015. PIV uncertainty propagation. Proc., 11th Int. Symp. Particle Image Velocimetry - PIV 15, Santa Barbara, 14-16 September. 
White, F. M., 1991. Viscous fluid flow, 2nd ed. Boston: McGraw-Hill, Sec. 4-6.6. 